\title{
Warming Patterns Affect EI Niño Diversity in CMIP5 and CMIP6 Models
}

\author{
MANDY B. FREUND \\ CSIRO Agriculture and Food, Melbourne, and School of Earth Sciences, University of Melbourne, and \\ Climate and Energy College, University of Melbourne, Parkville, Victoria, Australia
}

JOSEPHINE R. BROWN

School of Earth Sciences, University of Melbourne, and ARC Centre of Excellence for Climate Extremes, University of Melbourne, Parkville, Victoria, Australia

\section{BENJAMIN J. HENLEY}

School of Earth, Atmosphere and Environment, Monash University, Clayton, and School of Earth Sciences, University of Melbourne, and ARC Centre of Excellence for Climate Extremes, University of Melbourne, Parkville, Victoria, Australia

\section{DAVID J. KAROLY}

National Environmental Science Programme, Earth Systems and Climate Change Hub, CSIRO, Aspendale, Victoria, Australia

JACLYN N. BROWN

CSIRO Oceans and Atmosphere, Hobart, Tasmania, Australia

(Manuscript received 6 December 2019, in final form 25 May 2020)

\begin{abstract}
Given the consequences and global significance of El Niño-Southern Oscillation (ENSO) events it is essential to understand the representation of El Niño diversity in climate models for the present day and the future. In recent decades, El Niño events have occurred more frequently in the central Pacific (CP). Eastern Pacific (EP) El Niño events have increased in intensity. However, the processes and future implications of these observed changes in El Niño are not well understood. Here, the frequency and intensity of El Niño events are assessed in models from phases 5 and 6 of the Coupled Model Intercomparison Project (CMIP5 and CMIP6), and results are compared to extended instrumental and multicentury paleoclimate records. Future changes of El Niño are stronger for CP events than for EP events and differ between models. Models with a projected La Niña-like mean-state warming pattern show a tendency toward more EP but fewer CP events compared to models with an El Niño-like warming pattern. Among the models with more El Niño-like warming, differences in future El Niño can be partially explained by Pacific decadal variability (PDV). During positive PDV phases, more El Niño events occur, so future frequency changes are mainly determined by projected changes during positive PDV phases. Similarly, the intensity of El Niño is strongest during positive PDV phases. Future changes to El Niño may thus depend on both mean-state warming and decadal-scale natural variability.
\end{abstract}

\section{Introduction}

Globally, interannual climate variability is predominantly influenced by the coupled interactions of ocean and atmosphere driven by El Niño-Southern Oscillation (ENSO). The livelihoods of millions of people are

Corresponding author: Mandy B. Freund, mandy.freund@csiro.au affected by ENSO's anomalous warm phase (El Niño) and cool phase (La Niña). During these anomalous phases, the impacts on temperature and precipitation are often of dramatic extent, influencing entire harvesting seasons (Iizumi et al. 2014; Anderson et al. 2019), economies (Cashin et al. 2017), human health (Anyamba et al. 2019), and climate extremes across the globe (Ward et al. 2014). 
El Niño events can be characterized by two different warming patterns, differentiated by the location of the maximum sea surface temperature anomalies (SSTA). Canonical eastern Pacific (EP) El Niño events exhibit their largest SSTAs in the far eastern tropical Pacific (Rasmusson and Carpenter 1982). In the case of central Pacific (CP) El Niño events, also referred to as warm pool (Kug et al. 2009; Kao and Yu 2009), date line (Larkin and Harrison 2005), or El Niño Modoki (Ashok et al. 2007), the maximum SSTAs are located in the central Pacific.

Evidence is emerging that El Niño has recently changed its behavior. An increasing number of CP El Niño events have been observed during the most recent decades of the instrumental period (Yeh et al. 2009; Kug et al. 2009; Lee and McPhaden 2010; McPhaden et al. 2011; Freund et al. 2019). Coral-based reconstructions of El Niño over the past four centuries provide evidence that the increase of CP events since the 1980s is unusual in a multicentury context (Freund et al. 2019). However, the mechanisms leading to the increased proportion of CP El Niño events remain highly uncertain (Capotondi et al. 2015). Most studies investigating future changes of El Niño diversity using coupled general circulation models (CGCMs) show a lack of model agreement (Collins et al. 2010; Kim and Yu 2012; Taschetto et al. 2014; Chen et al. 2017). Systematic model biases, particularly in the equatorial Pacific, provide a challenge for the representation of ENSO diversity (Brown et al. 2015; Bayr et al. 2017) and often result in an underestimation of ENSO diversity (Ham and Kug 2011; Timmermann et al. 2018). Decadalscale variability in ENSO behavior adds further uncertainty to models' representation of ENSO (Wittenberg 2009; Choi et al. 2011; Newman et al. 2011; Yeh et al. 2011).

Efforts to understand the mechanisms underlying CP and EP events are hindered by model biases, a lack of model agreement, and the dearth of long-term observations. Furthermore, proposed mechanisms may be superimposed, and act on different time scales that range from weeks to decades. For example, subseasonal and stochastic processes such as differences in equatorial wind anomalies (Chen et al. 2015), zonal advection (Yeh et al. 2009), and shifts of convection centers (Stuecker et al. 2013) may influence the type of El Niño. Stochastic forcing preconditioned by initial conditions like an anomalous ocean heat excess has also been shown to influence the El Niño type (Timmermann et al. 2018).

Alternatively, long-term mean-state changes may also play an important role in favoring a certain type of El Niño. For example, the weakening of easterly trade winds (Vecchi et al. 2006), accelerated central equatorial sea surface warming (Karnauskas et al. 2009), enhanced interannual variability in the central Pacific (Liu et al. 2017), and a shoaling thermocline (Collins et al. 2010) could promote more CP El Niño events to occur.

On decadal to multidecadal time scales, tropical and extratropical circulation patterns in the North (Di Lorenzo et al. 2010) and South Pacific (Tatebe et al. 2013; Zhang et al. 2014), Indian Ocean (Luo et al. 2012), and the Atlantic (Ham et al. 2013) are thought to promote favorable conditions for one of the two types of El Niño (Sullivan et al. 2016; Chung and Li 2013).

The central question still remains, however: what processes contribute to changes in intensity and frequency of EP and CP El Niño events in historical and future climates? Here we consider the influence of three long-term and large-scale characteristics: mean global warming rates, differentiated zonal SST warming, and Pacific Ocean multidecadal variability.

Given that recent observed increases in the frequency of CP events appear to be associated with global mean temperature warming trends, do models that simulate greater warming show larger changes in $\mathrm{CP}$ and $\mathrm{EP} \mathrm{El}$ Niño frequency? Sensitivity experiments using CGCMs have already hypothesized strong nonlinear responses of ENSO to sea level pressure changes (Frauen et al. 2014) and global precipitation rates (Collins et al. 2010). phase 6 of the Coupled Model Intercomparison Project (CMIP6) models, for which climate sensitivity has strongly increased in many cases (Gettelman et al. 2019), may therefore exhibit more pronounced differences than the previous generation of models.

Differentiated warming of the eastern and western equatorial Pacific can lead to "El Niño-like" and "La Niña-like" warming patterns, when the eastern/western Pacific warms faster than the western/eastern (Sun and Liu 1996; An et al. 2011; Cane et al. 1997; Collins and Groups 2004). Do models with a more El Niño-like or La Niña-like mean-state change show larger changes in CP or EP event frequency? El Niño-like SST warming trends are often associated with a weakening Walker circulation (Held and Soden 2006) and eastward shift of the Walker circulation (Bayr et al. 2014). Whereas a La Niña-like warming trend has been associated with a strengthening Walker circulation (Kosaka and Xie 2013; Seager et al. 2019) and increased strong El Niño events (Wang et al. 2019). Models that capture observed ENSO nonlinearity may simulate a La Niña-like trend when ENSO amplitude is reduced (Kohyama et al. 2017).

In addition to trends in the long-term mean state, Pacific decadal variability (PDV) (Liu and Lorenzo 2018) associated with the Pacific decadal oscillation (PDO) (Mantua et al. 1997)/interdecadal Pacific oscillation (IPO) (Power et al. 1999; Henley et al. 2015) may 
play a role in modulating, or being modulated by, ENSO (Newman et al. 2003). Do models show stronger changes of El Niño events during PDV positive/negative phases? Early work has associated an increase in CP events with a positive PDV phase (Graham 1994; Hare and Mantua 2000; Trenberth and Stepaniak 2001), but since 1999, an increase of CP events coincides with a shift of PDV to a negative phase (Hu et al. 2013; Guan and McPhaden 2016; Lübbecke and McPhaden 2014). Thereby, Pacific decadal variability may be an important contributor to the occurrence of CP and possibly EP events (Sullivan et al. 2016; McPhaden et al. 2011; Zhao et al. 2016).

In this study, we investigate the SST characteristics that contribute to future changes of both El Niño types. We consider individual model responses and assess whether future changes of EP and CP El Niño in CMIP5 and CMIP6 model experiments are related to individual models' (i) global warming rate, (ii) mean-state changes of the zonal SST gradient, and (iii) Pacific decadal variability. We compare the frequency, variability, and intensity of simulated El Niño events to multicentury $\mathrm{CP}$ and EP El Niño reconstructions and the most recent observed changes (Freund et al. 2019) and highlight the differences between the unforced preindustrial control and forced future simulations.

\section{Datasets and methods}

\section{a. Observations and long-term reconstruction}

The gridded $\left(1^{\circ} \times 1^{\circ}\right)$ dataset of monthly sea surface temperatures HadISST, version 1.1 (Rayner et al. 2003), is used as a reference for observed conditions in the tropical Pacific from 1870 to 2016. Monthly SSTA are calculated spatially in the domain $\left(15^{\circ} \mathrm{N} / \mathrm{S}, 140^{\circ} \mathrm{E}-75^{\circ} \mathrm{W}\right)$ and for the Niño-3 $\left(5^{\circ} \mathrm{N}-5^{\circ} \mathrm{S}, 150^{\circ}-90^{\circ} \mathrm{W}\right)$ and Niño-4 $\left(5^{\circ} \mathrm{N}-5^{\circ} \mathrm{S}, 160^{\circ} \mathrm{E}-150^{\circ} \mathrm{W}\right)$ regional averages by subtracting the monthly climatology (1920-2016). Based on the Niño-3 and Niño-4 indices, we derive a monthly CP index and EP index [(1)] following Ren and Jin (2011), as a measure of $\mathrm{CP}$ and $\mathrm{EP}$ variability.

In addition to the instrumental record of observed $\mathrm{El}$ Niño events, we also use a multicentury record (16172008) of El Niño events reconstructed from ENSOsensitive proxy records as a long-term reference (Freund et al. 2019). The palaeoreconstruction (Recon) of different types of El Niño events over this period gives an estimate of the natural variability of $\mathrm{CP}$ and EP events prior to the instrumental record.

\section{b. CMIP models}

We assess simulated ENSO behavior and El Niño diversity in coupled global climate models (CGCMs) taking part in CMIP5 (Taylor et al. 2012) and CMIP6 (Eyring et al. 2016). We use monthly sea surface temperature from 51 climate models (Table A1). The CMIP experiments include long-term simulations of global climate prior to the industrial period (preindustrial control) covering at least 300 years (Eyring et al. 2016) and simulations of future conditions over the twentyfirst century. CMIP5 models simulate the 2006-2100 period following differing emission scenarios represented by the representative concentration pathways (RCPs). We focus on the high emissions scenario, RCP8.5 (Meinshausen et al. 2011) due to a higher expected signalto-noise ratio. CMIP6 models simulate future conditions in the period from 2016 to 2100 based on shared socioeconomic pathways (SSPs). The SSP5-8.5 scenario has similar forcing levels to RCP8.5 (Meinshausen et al. 2020). We assess simulated ENSO behavior and compare changes in projected El Niño diversity based on these two similarly high emission scenarios.

\section{c. Zonal sea surface temperature gradient and decadal variability}

Mean-state changes are estimated by the change of the annual zonal sea surface temperature gradient (ZSG) following Kohyama et al. (2017). The zonal sea surface temperature gradient represents the differentiated warming of the eastern and western portion of the upper equatorial ocean as the difference of Niño-3 minus Niño-4 SSTA. A change toward more positive ZSG indicates a stronger warming in the eastern Pacific compared to the central Pacific. Therefore, a positive long-term trend in ZSG can be understood as a "El Niño-like mean-state warming" that is possibly related to a weakening of the Walker circulation. In contrast, a trend toward negative ZSG can be understood as a "La Niña-like mean-state warming" that has been believed to be associated with a strengthening of the Walker circulation (Kohyama and Hartmann 2017). By computing the ZSG index in the CMIP models, we can differentiate the models by the mean-state warming pattern (El Niño/La Niña-like warming). We note that a trend of the ZSG can be influenced by a high degree of internal SST variability (Solomon and Newman 2012; Coats and Karnauskas 2017) and different measures of mean-state changes could be considered in future.

Decadal-scale variations in the Pacific are measured by the different phases of the interdecadal Pacific oscillation using the tripole index (TPI) (Henley et al. 2015) smoothed by a 13-yr Chebyshev low-pass filter (Fig. 1).

\section{d. El Niño identification and distinction}

Here we identify El Niño events and distinguish between $\mathrm{CP}$ and EP event types in observations, reconstructions and 


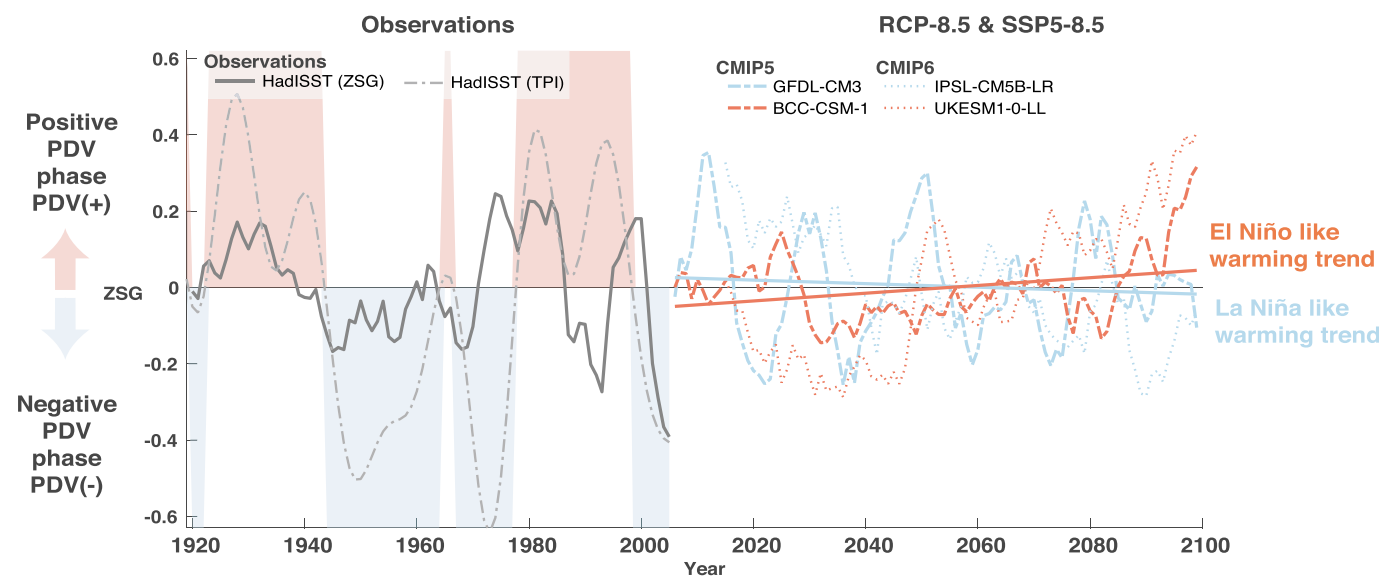

FIG. 1. Trends and changes of the ZSG index smoothed by a 7-yr running mean following Kohyama et al. (2017) and the TPI index in observations (HadISST, 1870-2016) and CMIP models in the future scenario runs RCP8.5 and SSP5-8.5 until 2100. Two selected models from the CMIP5 and CMIP6 phase are shown that represent El Niño/La Niña-like warming trends estimated by the least squares best-fit trend line in the future scenario run. Shading highlights observed periods of positive/negative PDV phases based on the TPI index.

climate model simulations using the Niño warm pool (NWP or CP index) and Niño cold tongue (NCT or EP index) indices (Ren and Jin 2011). Based on piecewise linear combination of Niño-3 $\left(N_{3}\right)$ and Niño-4 $\left(N_{4}\right)$ SSTA, the Niño SST indices are conditioned by the ENSO phase. Here we calculate the $\mathrm{EP}$ and $\mathrm{CP}$ index from monthly datasets following the calculation:

$$
\left\{\begin{array}{l}
\mathrm{EP}_{\text {index }}=N_{3}-\alpha N_{4} \\
\mathrm{CP}_{\text {index }}=N_{4}-\alpha N_{3},
\end{array}, \alpha=\left\{\begin{array}{c}
2 / 5, N_{3} N_{4}>0 \\
0, \text { otherwise }
\end{array} .\right.\right.
$$

These El Niño indices are aggregated to seasonal means for MAM, JJA, SON, and DJF and have previously been used to infer event classification (Freund et al. 2019; Yeh et al. 2015). The classification tree identifies three categorical classes at an annual time step: EP El Niño, CP El Niño, and nonEl Niño (neutral and La Niña) events using seasonal thresholds of the eight predictor variables (four seasons, preceding and current, two indices). The identification of events follows decisions that rely on consecutive seasons, whereby both El Niño indices are normalized within a moving window of 30 years length. EP El Niño events are identified when the SSTs in the eastern Pacific are elevated, so that the EP index exceeds a threshold (EP index $\geq 1.35$ ) during SON. CP El Niño events are identified if the SSTs in the eastern Pacific are slightly warmer than usual ( $\mathrm{CP}$ index $>0.11$ and $\leq 1.35$ ), and peak warming occurs in the central Pacific, so that the CP index exceeds a threshold (CP index $\geq 0.59$ ) in DJF. For more details on this methodology, see Freund et al. (2019).
The trained classification algorithm is applied to the climate model output by using model-simulated EP and $\mathrm{CP}$ indices at seasonal resolution. Similarly to the observational indices, modeled index time series are seasonally averaged and adjusted to have stable mean and variance at decadal time scale by normalizing the indices within a moving window of 30 years length. We further assess the performance of this classification approach, including its ability to correctly identify and distinguish the EP and $\mathrm{CP}$ events using pattern correlations between the observed and identified model events. We use the decision tree classification to identify El Niño events, their frequency, character (type), and intensity. The event intensity is taken as the maximum SSTA during an El Niño event in DJF, calculated from the EP and CP indices into Niño-3 and Niño-4 SST anomalies.

\section{Model evaluation, ENSO representation, and biases}

The CMIP preindustrial control runs are examined with the aim of identifying better performing models and distinguishing them from heavily biased models. (A list of all model simulations with available monthly surface temperatures hereinafter referred to as SST are shown in Table A1.) The goal is to subset the available models based on their performance in the preindustrial control simulations and use this subset for further analysis. Ultimately, a single better performing model for each modeling center is selected to avoid including multiple models with very similar components (Knutti et al. 2013). 

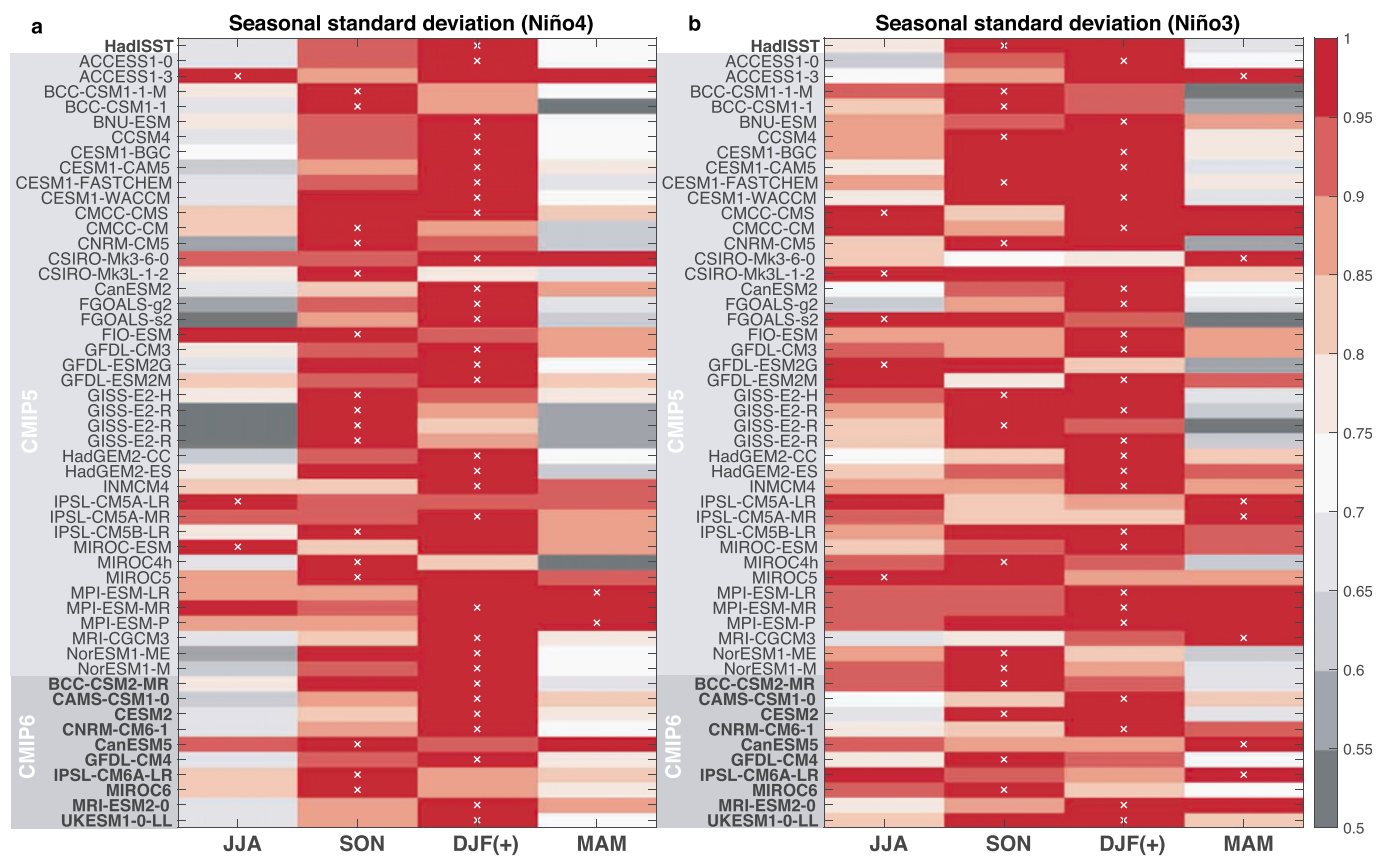

FIG. 2. Seasonal phase locking in CMIP models. Standard deviation of (a) Niño-4 and (b) Niño-3 for instrumental record (HadISST) and CMIP5 and CMIP6 models, normalized by their maximum value. Peak season given by the maximum is indicated with white crosses.

Although there are a number of different aspects of the tropical ocean and atmosphere system that must be simulated correctly to realistically represent ENSO in CGCMs (Wittenberg et al. 2006), we consider only the errors and biases of surface conditions expressed by SST to realistically simulate El Niño variability and diversity. In our study, the distinction of El Niño types depends mostly on the correct temporal and spatial representation of these surface conditions. We therefore focus on the correct representation of seasonal phase locking, the location of SST anomalies and the possibility of a secondary peak in zonal SST variability (Graham et al. 2017). Consequently, all models are evaluated based on three criteria:

- Seasonal phase locking: Strongest variability in Niño-3 and Niño-4 occurs during SON or DJF.

- Location of variability: Equatorial SST variability peaks east of $150^{\circ} \mathrm{W}$.

- Absence of a dominant secondary peak in SST variability: Zonal secondary peak that is below $50 \%$ of the maximum SST variability $\left(2^{\circ} \mathrm{N}-2^{\circ} \mathrm{S}\right)$.

\section{a. Seasonal phase locking}

We assess the ability of CMIP models to simulate the seasonal phase locking of El Niño events by calculating the standard deviations of SST during different seasons and in different regions [Fig. 2, Niño-4 (left) and Niño-3 (right)]. Instrumental data (HadISST) shows that both regions display the strongest variability and peak warming during austral spring (SON) and summer (DJF) (Fig. 2), respectively (Chang et al. 1994; Tziperman et al. 1994; Neelin et al. 2000). Most models capture central Pacific (Niño-4) seasonality better than in the eastern region (Niño-3). Out of 51 CMIP models, 46 show strongest variability during SON and DJF for the Niño-4 index (Fig. 2a), while only 39 models correctly reflect seasonal phase locking in the eastern Pacific (Niño-3) (Fig. 2b). Among the CMIP5 models, ACCESS1.3 and IPSL-CM5A-LR are unable to represent realistic ENSO behavior regarding seasonality in both regions. This strong phase bias could be associated with the overall weak annual cycle indicated by low interseasonal variations in standard deviations in these models. Other models with a weak annual cycle include the MPI models (MPI-ESM-LR, MPIESM-MR, MPI-ESM-P), which compared well with the observed seasonality in the eastern Pacific but not always in the central Pacific. From phase 5 to phase 6 , the IPSL-CM6A-LR model shows an improvement in representing the central Pacific (Niño-4) but not the eastern Pacific (Niño-3). Overall, most CGCMs represent the synchronization of ENSO to the seasonal cycle similar to the observed (Bellenger et al. 2014; Lloyd et al. 2009; Guilyardi 2005; Taschetto et al. 2014). Alternative methods to quantify seasonal phase 
TABLE 1. CMIP models available for model evaluation. The performance of each model is evaluated based on the control simulations of surface temperatures. The model's ability to simulate each criterion is marked by a circle where filled circles indicate passing and nonfilled circle failing criteria. Models in bold are used for further analysis.

\begin{tabular}{|c|c|c|c|c|}
\hline \multirow[b]{2}{*}{ Model } & \multicolumn{2}{|c|}{ Seasonality } & \multirow[b]{2}{*}{ Location } & \multirow[b]{2}{*}{ Single peak } \\
\hline & Niño-3 & Niño-4 & & \\
\hline ACCESS1.0 & $\bullet$ & $\bullet$ & $\bullet$ & $\bullet$ \\
\hline ACCESS1.3 & $\bigcirc$ & $\bigcirc$ & $\bullet$ & 0 \\
\hline BCC-CSM1.1-M & - & - & - & - \\
\hline BCC-CSM1.1 & - & - & - & - \\
\hline BNU-ESM & $\bullet$ & $\bullet$ & $\bullet$ & $\bullet$ \\
\hline CCSM4 & $\bullet$ & $\bullet$ & $\bullet$ & $\bullet$ \\
\hline CESM1-BGC & $\bullet$ & $\bullet$ & $\bullet$ & $\bullet$ \\
\hline CESM1-CAM5 & $\bullet$ & $\bullet$ & $\bullet$ & $\bigcirc$ \\
\hline CESM1-FASTCHEM & $\bullet$ & $\bullet$ & $\bullet$ & $\bullet$ \\
\hline CESM1-WACCM & $\bullet$ & $\bullet$ & $\bullet$ & $\bullet$ \\
\hline CMCC-CMS & $\bigcirc$ & $\bullet$ & $\bullet$ & $\bullet$ \\
\hline CMCC-CM & $\bullet$ & $\bullet$ & $\bullet$ & $\bullet$ \\
\hline CNRM-CM5 & $\bullet$ & $\bullet$ & $\bullet$ & $\bullet$ \\
\hline CSIRO-Mk3.6-0 & 0 & - & 0 & - \\
\hline CSIRO-Mk3L-1.2 & $\bigcirc$ & $\bullet$ & O & $\bullet$ \\
\hline CanESM2 & $\bullet$ & $\bullet$ & $\bullet$ & $\bullet$ \\
\hline FGOALS-g2 & $\bullet$ & $\bullet$ & $\bullet$ & $\bullet$ \\
\hline FGOALS-s2 & O & $\bullet$ & $\bullet$ & $\bullet$ \\
\hline FIO-ESM & $\bullet$ & $\bullet$ & $\bullet$ & $\bullet$ \\
\hline GFDL-CM3 & $\bullet$ & $\bullet$ & $\bullet$ & $\bullet$ \\
\hline GFDL-ESM2G & O & $\bullet$ & $\bullet$ & O \\
\hline GFDL-ESM2M & $\bullet$ & $\bullet$ & $\bullet$ & $\bullet$ \\
\hline GISS-E2-H & $\bullet$ & $\bullet$ & $\bullet$ & $\bullet$ \\
\hline GISS-E2-R & $\bullet$ & $\bullet$ & O & $\bullet$ \\
\hline GISS-E2-R & $\bullet$ & $\bullet$ & O & $\bullet$ \\
\hline GISS-E2-R & $\bullet$ & $\bullet$ & O & $\bullet$ \\
\hline HadGEM2-CC & $\bullet$ & $\bullet$ & $\bullet$ & $\bullet$ \\
\hline HadGEM2-ES & $\bullet$ & $\bullet$ & $\bullet$ & $\bullet$ \\
\hline INMCM4 & $\bullet$ & $\bullet$ & $\bullet$ & $\bullet$ \\
\hline IPSL-CM5A-LR & $\bigcirc$ & $\bigcirc$ & $\bullet$ & $\bullet$ \\
\hline IPSL-CM5A-MR & $\bigcirc$ & $\bullet$ & $\bullet$ & $\bullet$ \\
\hline IPSL-CM5B-LR & $\bullet$ & $\bullet$ & $\bullet$ & $\bullet$ \\
\hline MIROC-ESM & $\bullet$ & O & $\bullet$ & $\bullet$ \\
\hline MIROC4h & $\bullet$ & $\bullet$ & $\bigcirc$ & $\bullet$ \\
\hline MIROC5 & O & $\bullet$ & $\bullet$ & O \\
\hline MPI-ESM-LR & $\bullet$ & $\bigcirc$ & $\bullet$ & 0 \\
\hline MPI-ESM-MR & $\bullet$ & $\bullet$ & $\bullet$ & $\bullet$ \\
\hline MPI-ESM-P & $\bullet$ & $\bigcirc$ & $\bullet$ & O \\
\hline MRI-CGCM3 & O & $\bullet$ & $\bullet$ & $\bullet$ \\
\hline NorESM1-ME & $\bullet$ & $\bullet$ & $\bullet$ & $\bullet$ \\
\hline NorESM1-M & $\bullet$ & $\bullet$ & $\bullet$ & $\bullet$ \\
\hline BCC-CSM2-MR(6) & $\bullet$ & $\bullet$ & $\bullet$ & $\bullet$ \\
\hline CNRM-CM6.1(6) & $\bullet$ & $\bullet$ & $\bullet$ & $\bullet$ \\
\hline CanESM5(6) & ○ & $\bullet$ & $\bullet$ & $\bullet$ \\
\hline GFDL-CM4(6) & $\bullet$ & $\bullet$ & $\bullet$ & $\bullet$ \\
\hline IPSL-CM6A-LR(6) & $\bigcirc$ & $\bullet$ & $\bullet$ & $\bullet$ \\
\hline MRI-ESM2.0(6) & $\bullet$ & $\bullet$ & $\bullet$ & $\bullet$ \\
\hline UKESM1.0-LL(6) & $\bullet$ & $\bullet$ & $\bullet$ & $\bullet$ \\
\hline
\end{tabular}

locking (appendix A) show similar behavior (Fig. A1). Therefore, we exclude the 13 CMIP5 models that do not exhibit their strongest variability in Niño-3 and Niño-4 during SON or DJF (Table 1) from further analysis.

\section{b. Location of main variability peak}

The zonal structure of observed SSTA variability (HadISST) shows ENSO's observed center of action in the eastern Pacific (Fig. 3). Along the equator, the interannual variability is strongest in the Niño-3 region and is reduced by approximately one-half to the west of the date line (Fig. 3). The observed center of action is located close to $110^{\circ} \mathrm{W}$ longitude indicated by a single peak in the annual standard deviation. For CMIP5 and CMIP6, the location and amplitude of the center of action vary substantially between models. Although the majority of model simulations show peak variability in he eastern Pacific, the amplitude is typically overestimated, by up to double the observed value (e.g., CMIP5 models FIO-ESM, BNU-ESM, BCC-CSM1.1M, CESM1-WACCM, and CMIP6 models CAMS-CSM-1.0, BCC-CSM-MR). The CMIP6 models are consistent in this overestimation of variability but show improvements. For instance, greatest improvements can be seen for the Canadian models, which in phase 5 (CanESM2) peaked too far west and improved in phase 6 (CanESM5) to one of the best models in terms of zonal variability structure. Contrary to models with wellcaptured patterns are models that show a reverse zonal pattern (CSIRO-Mk3.6-0 peaks in the tropical warm pool) or a displacement of the center of action into the central Pacific (CSIRO-Mk3L-1.2, MIROC4h, GISS-E2$\mathrm{R})$. This serves as an indicator of unusually high El Niño activity in the central Pacific and could therefore be mistaken for CP El Niño events. To distinguish El Niño events, the correct location is important while the absolute degree of variability is secondary due to the use of standardized indices. We therefore restrict our analysis to models that correctly simulate peak variability in the eastern Pacific (east of $150^{\circ} \mathrm{W}$ ); see Table 1 (we exclude 6 models).

\section{c. Absence of secondary peak in variability}

In addition to the displacement of the center of action, one of the most prominent systematic errors in the mean-state conditions in the tropical Pacific is the cold tongue bias ( $\mathrm{Li}$ and $\mathrm{Xie} 2014$ ) and with it often a "secondary peak" in equatorial SSTs during El Niño (Graham et al. 2017). The cold tongue bias, indicated by lower-than-observed SSTs in the western and central equatorial Pacific, shifts ENSO-related atmospheric responses such as deep convection too far west (Brown et al. 2013, 2015). The enhanced and displaced zonal temperature gradient consequently leads to a change in the zonal advective feedback (west Pacific) relative to the vertical advective feedback (east Pacific), which reinforces further warming. 


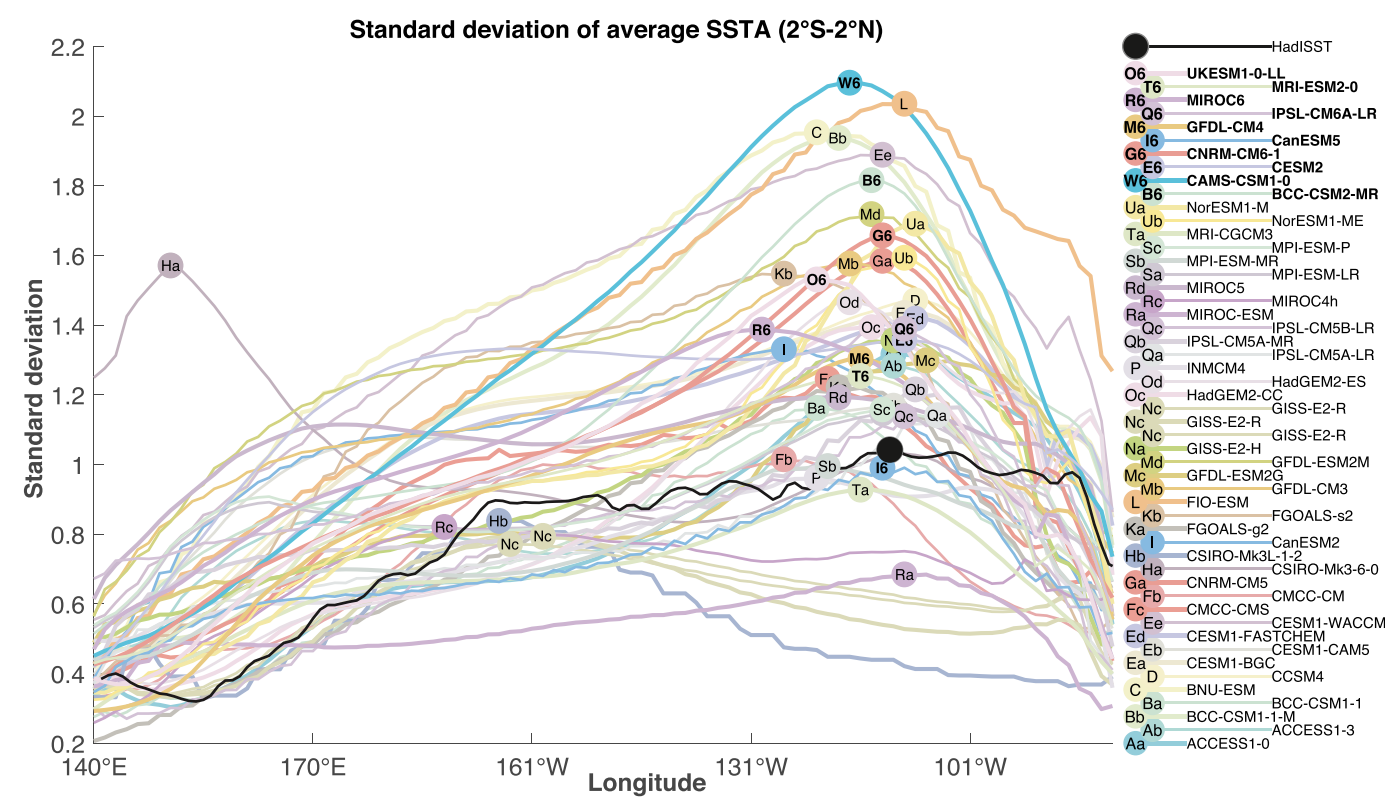

FIG. 3. Zonal SSTA variability in observations and CMIP preindustrial control simulations. Standard deviation in ${ }^{\circ} \mathrm{C}$ of monthly instrumental average SSTA $\left(2^{\circ} \mathrm{N}-2^{\circ} \mathrm{S}\right)$ based on 1920-2016 HadISSTv.1 data (Rayner et al. 2003) and simulated SSTA variability in CMIP5 models and CMIP6 models (bold). Naming markers are located at the maximum SSTA.

A secondary warming peak emerges in the western Pacific that manifests as a double-peaked pattern of SST warming (Graham et al. 2017). This double-peaked variability pattern is not consistent with observations.

An accurate distinction of EP and CP El Niño event types in CGCMs with a secondary warming peak may not be possible. To avoid the nonrealistic double-peak behavior in CGCMs, the simulations that show an extensive secondary peak are flagged (Table 1, single peak). We flag the simulations that have a secondary peak in variability farther to the west that is more than $50 \%$ of the magnitude of the primary peak in the east. Models with a secondary peak are, for CMIP5, ACCESS1.3, CESM1-CAM5, GFDL-ESM2G, MPI-ESM-P/-LR, and MIROC5. According to Graham et al. (2017), these models have previously shown a secondary peak in SST variability along the equator. Interestingly, none of the CMIP6 models considered here show a secondary peak behavior.

Overall, we find 23 CMIP5 and 7 CMIP6 models that adequately simulate the temporal and spatial representation of ENSO based on indices of mean state and ENSO variability. So, to summarize, satisfactory performance was measured by the seasonal phase locking, the location of maximum variability in SSTs and existence of a single dominant peak of SST variability (Table 1). We have selected one best performing CMIP5 model for each modeling center and included all available CMIP6 models to allow for comparison. This results in a total of 27 CMIP models that are used for further analysis of El Niño events.

\section{Characteristics of EI Niño events in CMIP models}

CP and EP El Niño events are identified using the decision tree in the each of the different simulations in the 27 CMIP models. We first assess the performance of our classification approach, including its ability to correctly identify and distinguish EP and CP El Niño types.

We furthermore check if the magnitude of simulated variability has an impact on the absolute number of identified El Niño events. Most of the models have shown larger simulated SST variability along the equator compared to observations (Fig. 3). We therefore compare the simulated variability in the Niño-3 and Niño-4 regions to the event frequency of EP and CP events (Figs. 4a,b). The magnitude of variability measured by the standard deviation across the models is largely independent of the absolute number of identified El Niño events (because the event definition uses a threshold normalized relative to the model's own variability). Models with a higher/lower degree of variability in the Niño-3 or Niño-4 regions do not show more/less El Niño events. Hence, the classification of El Niño 

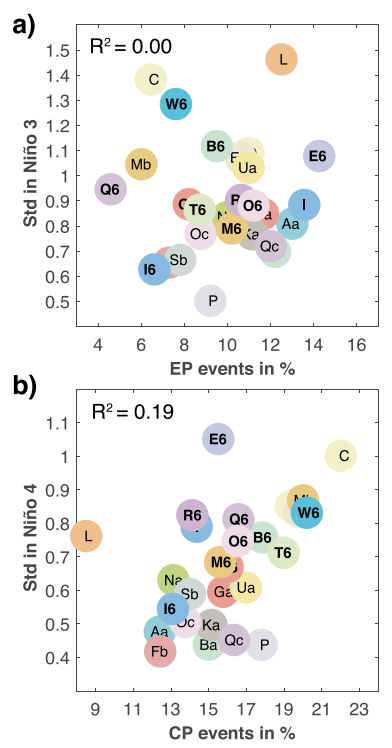
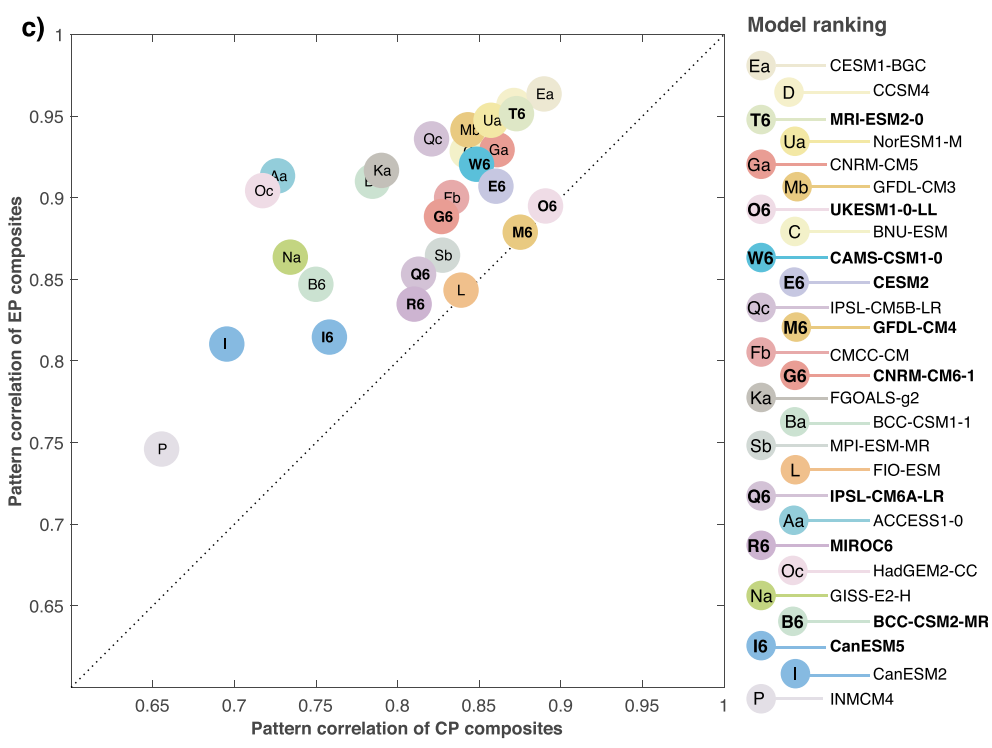

FIG. 4. Simulated El Niño statistics. Scatterplot of variability vs event frequency given by the standard deviation of (a) Niño-3 and (b) Niño-4 over the proportion of EP events and CP events by each model (preindustrial control). Linear regression fit is indicated by $R^{2}$. (c) Model ranking shown by the scatterplot of pattern correlations of the composites between the instrumental and the CMIP models for EP and CP El Niño events for DJF. Pattern correlations are based on the domain $\left(15^{\circ} \mathrm{N} / \mathrm{S}\right.$ and $\left.140^{\circ} \mathrm{E}-75^{\circ} \mathrm{W}\right)$.

events using normalized indices is unrelated to the magnitude of variability simulated by the individual models.

Finally, we assess how well the classification method captures the simulated spatial patterns of the two types of El Niño on average (Fig. 4c). Both El Niño types compare well with the observed pattern based on regional pattern correlation coefficients exceeding $r=0.7$ for all models. On average, the spatial pattern of EP variability (Fig. 5) is better captured than the CP pattern (Fig. 6). The regression fit between pattern correlations for different models suggests that models that have a better representation of EP El Niño tend to also show a better CP El Niño representation $\left(r^{2}=0.56\right)$. The best model in terms of pattern correlations, exceeding $r \geq 0.9$ for both types of El Niño, is the CESM1-BGC model (Ea), followed by CCSM4 (D), and the CMIP6 model MRI-ESM2.0 (T6). These models capture the observed spatial pattern of pronounced warming off the South American coast during EP years as well as the displacement of strongest SSTA in the central Pacific during CP years. Following from this analysis, the models in subsequent plots are ranked by their spatial performance for both EP and CP events based on their agreement with the observations. The ranking is based on the Euclidean distance between the origin and the point that corresponds to the pattern correlations of $\mathrm{EP}$ and $\mathrm{CP}$ events with the observations.

We have selected a set of models that are able to simulate $\mathrm{CP}$ and $\mathrm{EP}$ events and evaluated their performance and the use of our event classification scheme. We can now examine El Niño variability and intensity in model simulations considering the model ranking and different warming patterns.

\section{El Niño variability in CMIP models}

\section{a. Event frequency in observations and reconstruction}

Some previous studies have argued that the frequency of El Niño events may change in response to climate change (Yeh et al. 2009). More frequent observed CP El Niño events in recent decades (Lee and McPhaden 2010) have been suggested to be part of natural variations of ENSO (Newman et al. 2011) but appear unusual in a multicentury context (Freund et al. 2019). Given the short instrumental record and irregular occurrence of El Niño events, the estimation of natural variations from observed events is limited. We first compare the natural variations of El Niño in terms of event frequency based on two periods: the observational record (1870 to 2016) and the longer-term record provided by the paleoreconstruction (1617 to 2008). We then use the estimated range of variability from both records as a reference for the comparison with CMIP models and further to assess projected changes.

According to the application of our classification approach to the early instrumental records (1870-1980) 

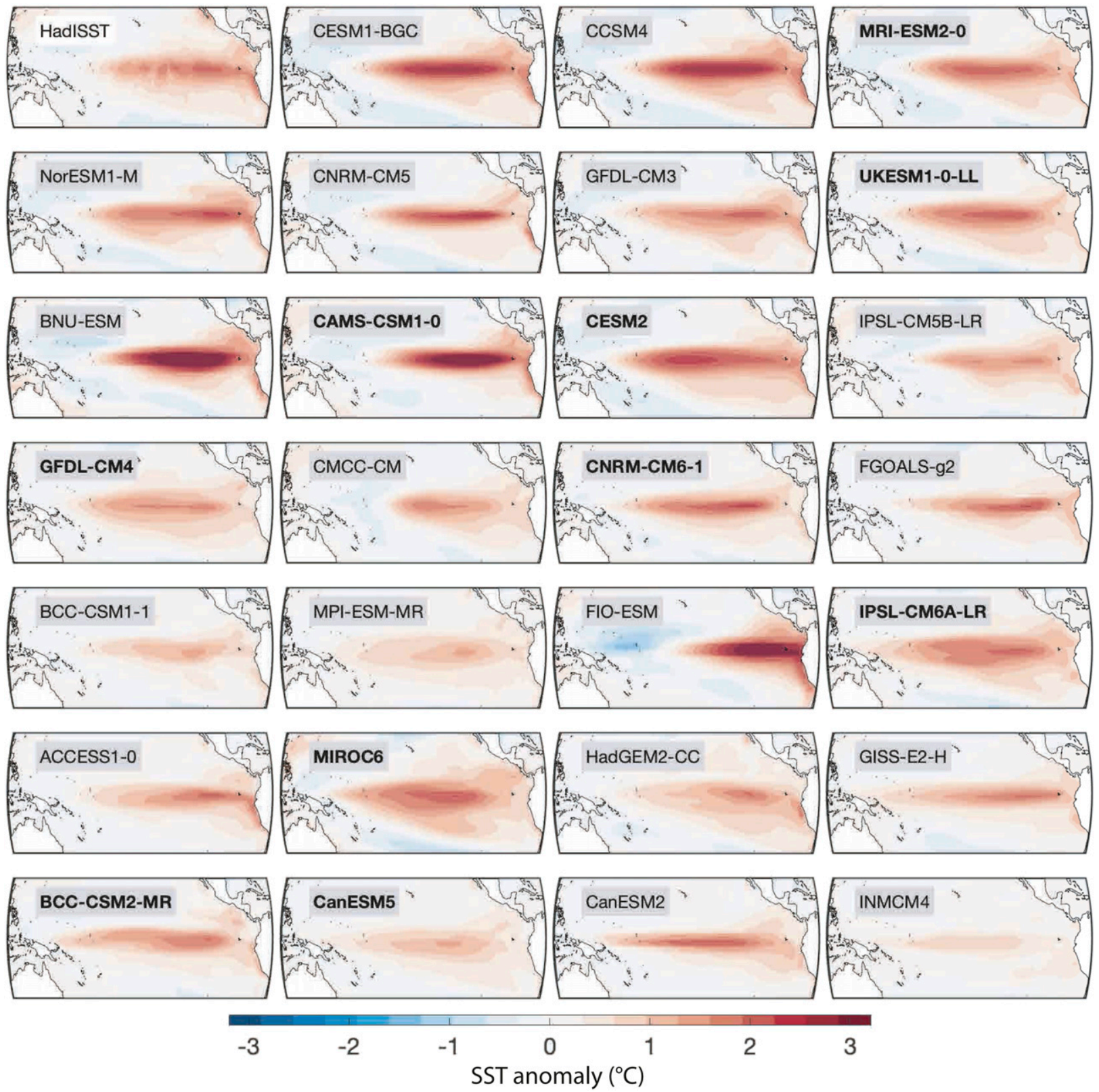

FIG. 5. Composite of SSTA during EP events. Composite of monthly SSTA for observed EP El Niño events (1951, 1957, 1965, 1972, 1976, 1982, 1986, 1997) and individual simulated EP El Niño events in the preindustrial control simulations of CMIP5 and CMIP6 (bold) models during DJF $\left(30^{\circ} \mathrm{N}-30^{\circ} \mathrm{S}, 70^{\circ} \mathrm{W}-120^{\circ} \mathrm{E}\right)$. Models are sorted in descending order according to the model ranking.

prior to significant changes (Freund et al. 2019), the frequency of EP (12.7\%) and CP El Niño events $(13.6 \%)$ is nearly identical and equates to a total of about $26 \%$ of years being classified as El Niño events (Figs. 7a,b). The proportion of reconstructed El Niño events prior to 1980 (Freund et al. 2019) is slightly less (21\%) compared to the early instrumental record (25\%) but agrees with the early instrumental record that shows slightly more CP events (12\%) compared to EP events $(9.4 \%)$.

\section{EVENT FREQUENCY IN CMIP MODELS}

Although the number of EP events in most models is similar to the number of observed and reconstructed events, the CMIP5 models GFDL-CM3, BNU-ESM, CMCC-CM, and MPI-ESM-MR and CMIP6 models MRI-ESM2.0, CNRM-CM6.1, CanESM5, and IPSLCM6A-LR substantially underrepresent the number of EP events in their preindustrial control simulations (Fig. 7a). In the case of the CanESM5 and IPSL-CM6A-LR models, this 

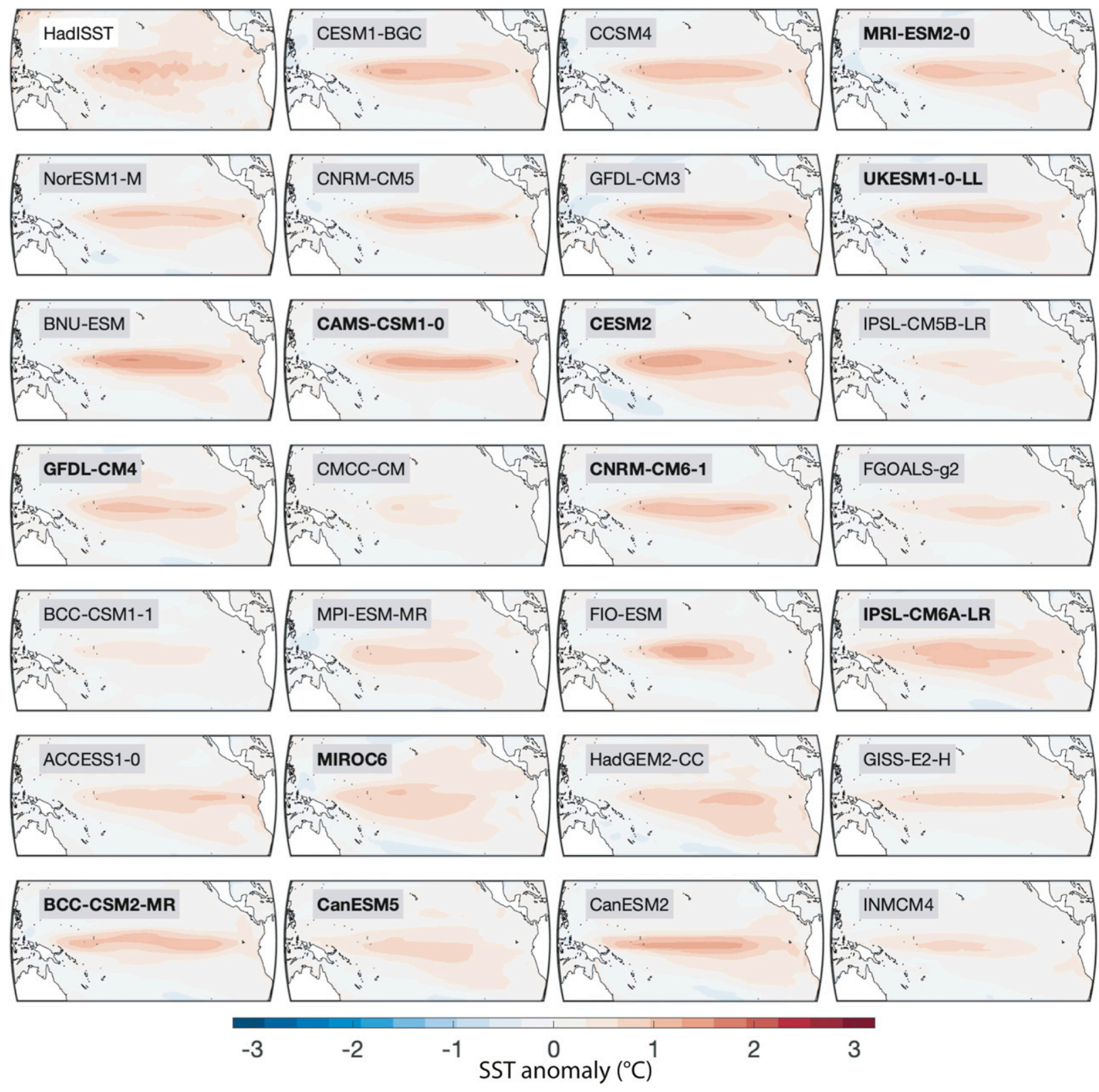

FIG. 6. Composite of SSTA during CP events. Composite of monthly SSTA for observed CP El Niño events (1963, 1968, 1977, 1979, 1987, 1991, 1994, 2002, 2004, 2009) and individual simulated CP El Niño events in the preindustrial control simulations of CMIP5 and CMIP6 (bold) models during DJF $\left(30^{\circ} \mathrm{N}-30^{\circ} \mathrm{S}, 70^{\circ} \mathrm{W}-120^{\circ} \mathrm{E}\right)$. Models are sorted in descending order according to the model ranking.

underrepresentation of EP events could be explained by displacement of seasonal variability in the Niño-3 region from DJF to MAM (Fig. 2). Furthermore, the overall underrepresentation of $\mathrm{EP}$ events in the preindustrial control simulations could also be due to a lack of external forcing such as volcanic forcing linked to ENSO events (Mann et al. 2005).

The proportion of CP El Niño events in better performing models tends to exceed the proportion of $\mathrm{CP}$ events represented by the instrumental and reconstructed record (Fig. 7b). Among the 9 best ranked models, the majority simulate more $\mathrm{CP}$ events in their preindustrial control simulations than observed but not necessarily more EP events than observed (Fig. 7a). At the same time, lower-ranked models tend to show fewer $\mathrm{CP}$ events than seen in the instrumental and reconstructed records.

The impact of anthropogenic forcing on the event frequency is investigated by comparing the high emission 

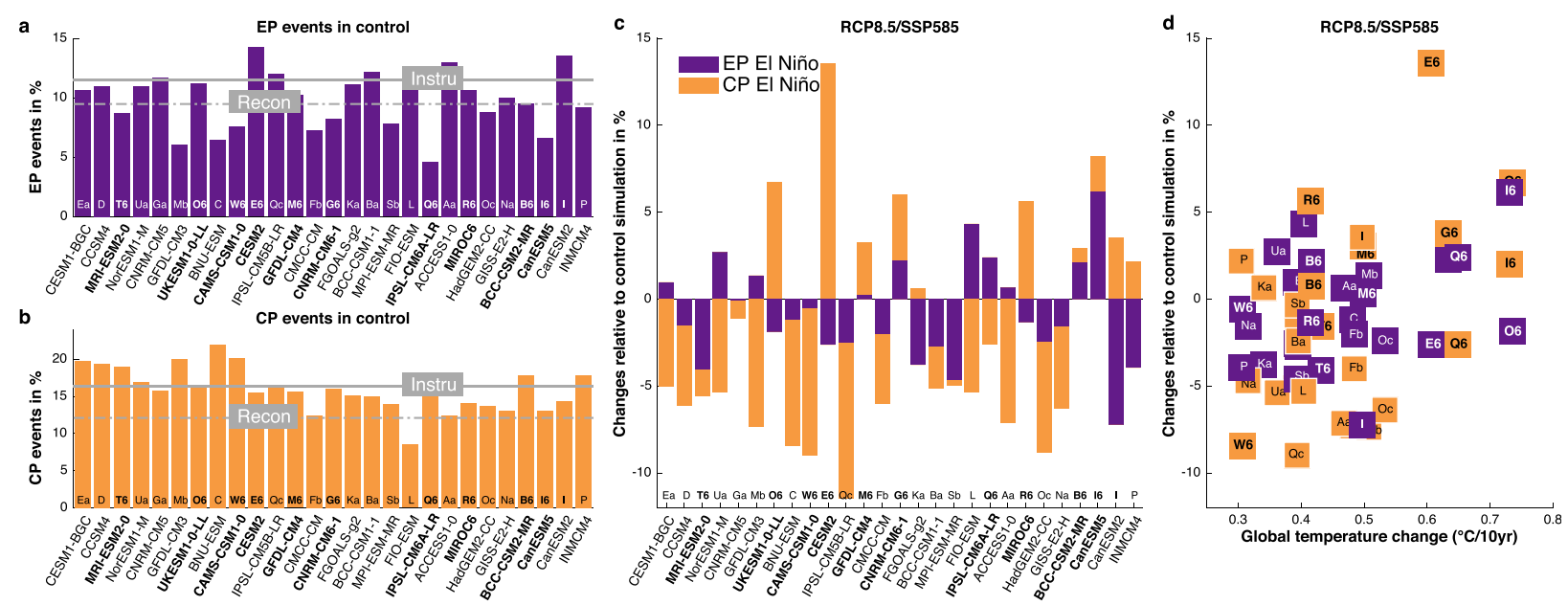

FIG. 7. Occurrence of different El Niño events and changes relative to preindustrial control. Number of (a) EP and (b) CP El Niño events given as \% of all years in preindustrial control simulations. Horizontal lines show the number of events in the instrumental record (1870-1980: solid) and the reconstruction (1617-1980: dashed). (c) Stacked changes are given as differences in percent relative to the preindustrial control simulation, so that positive/negative deviations indicate more events/fewer events in the future emissions scenario. Change values are derived from the RCP8.5/SSP5-8.5 scenario. (d) Change values are also shown as a function of the global mean temperature change in the RCP8.5/SSP5-8.5 scenario (not significant at $p<0.05$ ). Models are ranked from (left) best to (right) worst.

scenarios RCP8.5/SSP5-8.5 with the preindustrial control simulations (Fig. 7c). Most of the models show a decrease of $\mathrm{CP}$ events, but there is little agreement in the projection of changes of EP and $\mathrm{CP}$ event frequency across the models, as found in previous studies (Chen et al. 2017; Taschetto et al. 2014). In general, larger changes in event frequency are evident for $\mathrm{CP}$ events compared to $\mathrm{EP}$ events, which could indicate a stronger sensitivity of the central Pacific conditions toward external forcing. The proportion of EP events shows changes of mostly less than $7 \%$, whereas CP events indicate changes of up to $12 \%$ relative to the preindustrial control simulations.

We investigate further the role of anthropogenic forcing on changes in $\mathrm{CP}$ and EP event frequency by comparing the rate of temperature increase (a proxy for climate sensitivity) of the models (Fig. 7d). If changes in the number of El Niño events are driven by the overall amount of warming, models that warm faster/slower would simulate more/less El Niño events. Figure 7 shows that this is not the case. Changes in the number of $\mathrm{CP}$ or EP events are not linearly related to the degree of warming simulated in the RCP8.5/SSP5-8.5 scenarios at the 95\% confidence level using a $t$ test. This is dynamically significant and independent of the windowing approach. We conclude that the simulated temperature increase has no clear influence on the number of simulated El Niño events.

\section{b. Natural internal variability and projected changes of El Niño frequency in CMIP models}

The simulated range of variability of El Niño event occurrence is explored in the preindustrial control simulations and the unforced variability range is compared with changes simulated in the high emission scenarios, RCP8.5/SSP5-8.5. Based on the long-term paleoreconstruction, the natural frequency of EP events is larger than for CP events (Figs. 8a-c). The frequency of $\mathrm{CP}$ events varies very little in the past 400 years prior to 1980 but shows a strong increase in the most recent observed period based on the instrumental estimate (red dot in Fig. 8a). In the CMIP models, the preindustrial control simulations exhibit more variability of $\mathrm{CP}$ event frequency than seen in the reconstructions (Fig. 8d). In the CMIP preindustrial control simulations, the frequency of CP events is often similar to the frequency of EP events (Fig. 8e). This suggests that the natural variability of CP frequency is mostly overrepresented by the CMIP models and a number of models underestimate the natural variability of EP events. There is no significant dependency across the models between the natural variability of EP event frequency and the natural variability of CP event frequency $(r=-0.3)$. Similarly, there is no relationship to the overall performance of the model based on our ranking (not shown).

By concentrating on the $\mathrm{CP}$ to EP ratio, we can compare the relationship of both types of El Niño events simultaneously independent of model biases in total numbers of $\mathrm{El}$ Niño events. The natural variability of the ratio of $\mathrm{CP}$ to EP events is overall well captured by the preindustrial control simulations (Fig. 8f) and agrees with the reconstructed range (0.6-2.0) for the majority of models (Fig. 8c).

We now compare the projected future changes of $\mathrm{CP}$ and $\mathrm{EP}$ event frequency with the individual model range 


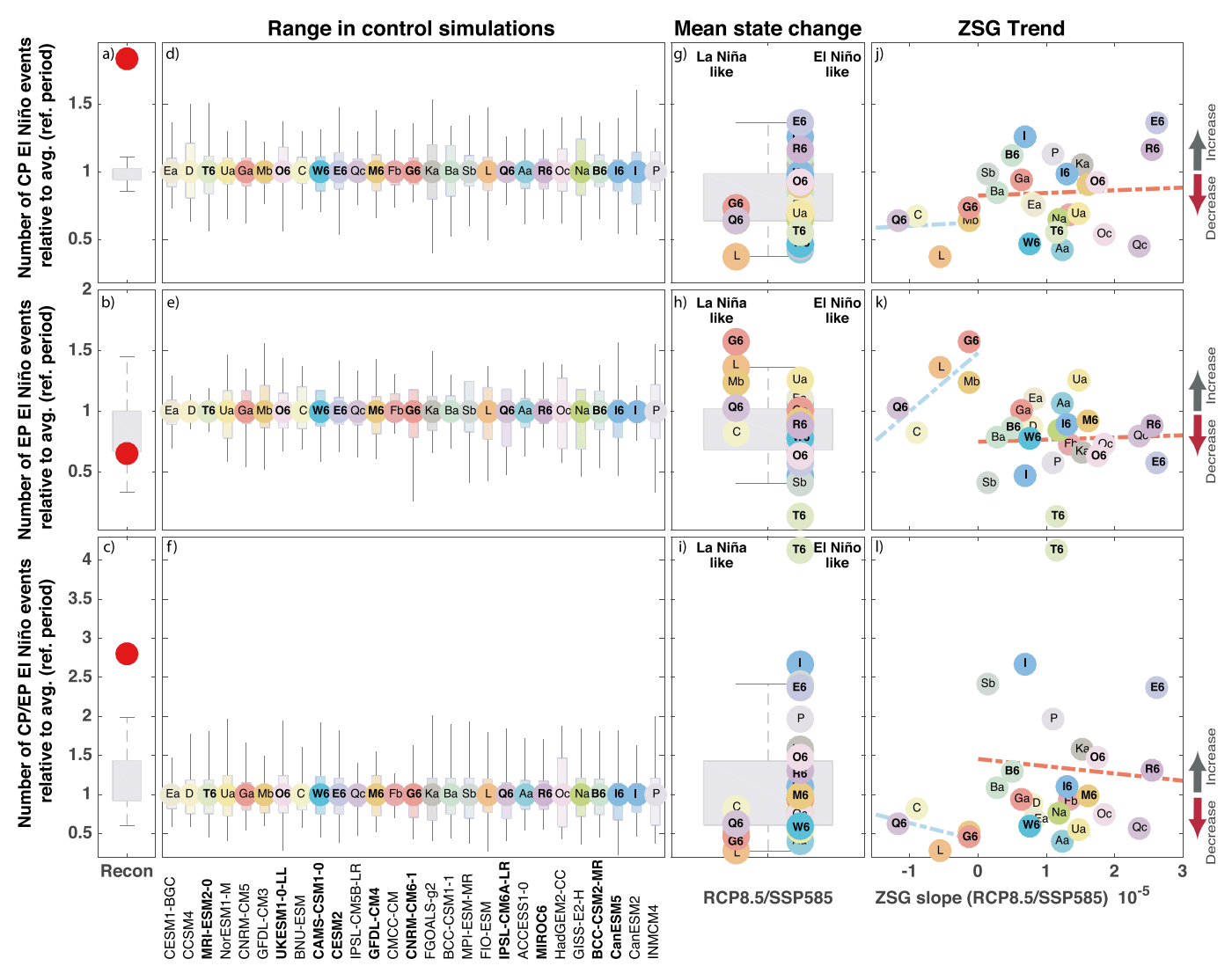

FIG. 8. Deviation changes of El Niño. Number of (a) CP and (b) EP events and the ratio of CP to EP events (c) expressed by the average conditions divided by the mean of each reference period, so that the deviations larger than 1 equal an increase/decrease relative to the reference mean. (a)-(c) Recent observations (1980-2016: red dot) relative to reconstructed variability derived from sliding window of 94 years relative to average reference period (1617-1980). (d)-(f) Event variability in preindustrial control simulations derived from sliding window of 94 years relative to its mean. (g)-(i) Average conditions in the RCP8.5/SSP5-8.5 scenario relative to the average preindustrial control simulations for all models (boxplot) and distinguished by models with a La Niña-like warming trend and El Niño-like warming trend derived from the ZSG slope during the RCP8.5/SSP5-8.5 period. (j)-(1) Changes relative to the preindustrial control simulations for individual models as a function of its ZSG slope in RCP8.5/SSP5-8.5. Regression lines are separated for El Niño- and La Niña-like warming models.

due to natural variability derived from the preindustrial control simulations. Changes between the control simulation and the simulations under emission scenarios RCP8.5 and SSP5-8.5 can give an indication how El Niño diversity may change in future due to global warming.

There is no consensus among the models toward an increase or decrease in EP and CP El Niños in the future simulations (Figs. 7b,c). Importantly, these changes are not related to the degree of model warming or the model performance measured by the ranking.

Instead, we differentiate the CMIP models by their mean-state change in response to warming. The majority of CMIP5 and CMIP6 models warm faster in the eastern tropical Pacific than the western tropical Pacific, often referred as an El Niño-like warming pattern. Out of our 27 considered CMIP models, only 5 show a La Niñalike warming pattern (BNU-ESM, FIO-ESM, GFDL-CM3, CNRM-CM6.1, IPSL-CM6A-LR) of which the latter two are from CMIP6. When grouped by the mean-state change, all La Niña-like warming models show a reduction in CP events in the future simulations compared to the control simulations (Fig. 8g). At the same time, the majority of La Niña-like warming models (4 out of 5) show more EP events in the future simulations compared to preindustrial control (Fig. 8h) resulting in an overall lower ratio of $\mathrm{CP}$ to EP events in future scenarios (Fig. 8i).

However, the change in El Niño events for El Niñolike warming models is not as clear and shows changes of opposing sign. Although the strongest changes in terms of CP frequency increase and EP frequency decrease occur for El Niño-like warming models, they are not 


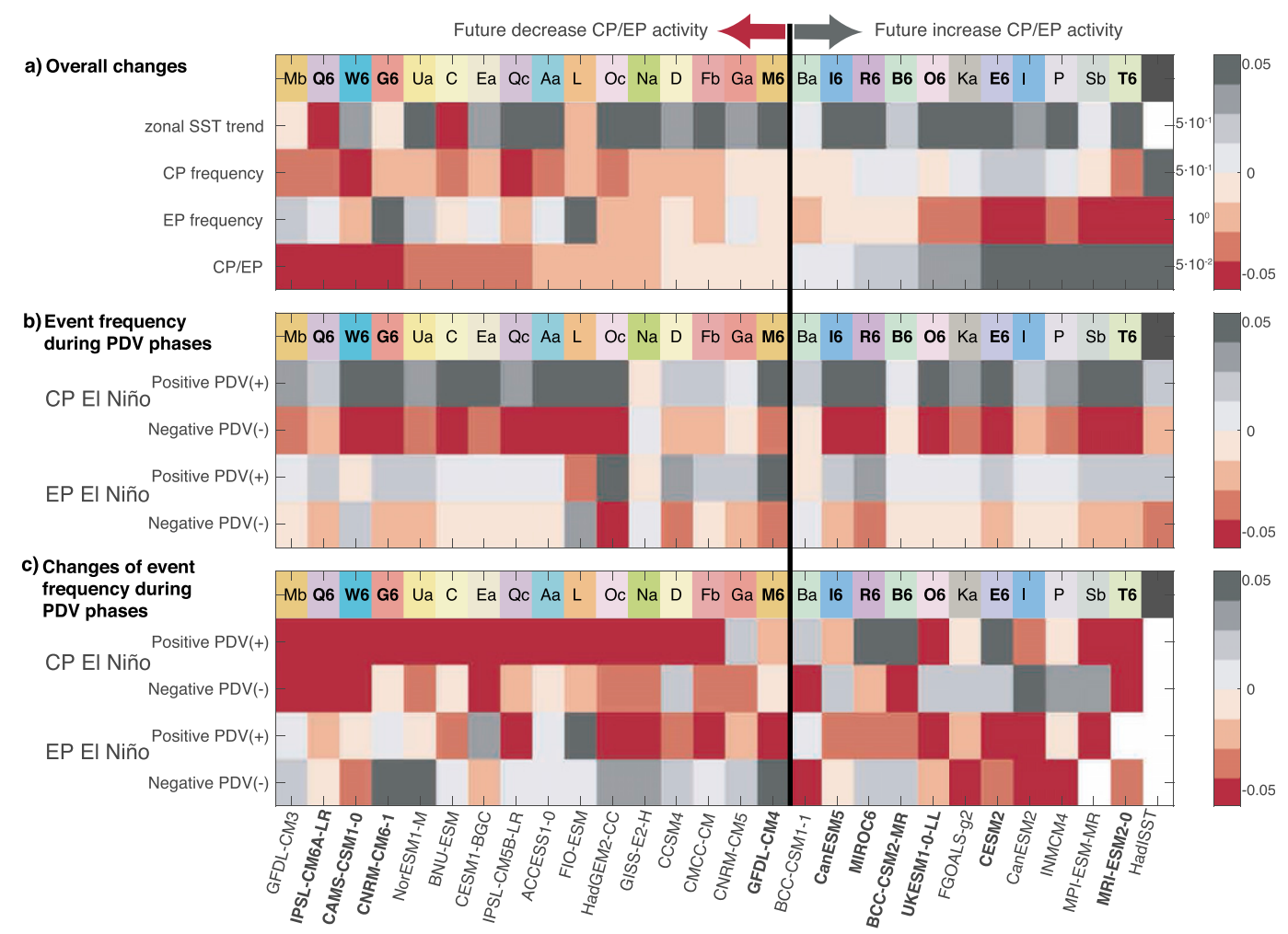

FIG. 9. Changes of El Niño frequencies and PDV phases. (a) Summary of the zonal SST trend in the future simulations (positive/negative: El Niño/La Niña-like warming pattern) and changes of event frequency of $\mathrm{CP}$ events, EP events and the overall ratio of CP/EP events as the difference between RCP8.5/SSP5-8.5 and preindustrial control simulations for 27 CMIP models and the early (1870-1980) and late (1981-2016) instrumental HadISST record. CMIP5 and CMIP6 (bold) models are sorted according to their CP/EP ratio (fourth row). (b) Difference of event frequency of CP and EP El Niño events during positive PDV and negative PDV periods in the preindustrial control simulations relative to the individual model event frequency derived from the preindustrial control simulations and the entire instrumental HadISST record (1870-2016). (c) Difference between the event frequency of $\mathrm{CP}$ and EP events during PDV positive and PDV negative periods derived from the preindustrial control simulations and the RCP8.5/SSP5-8.5 simulations.

consistent across the group. A similar number of $\mathrm{El}$ Niño-like warming models simulate the ratio of CP to EP events to increase as to decrease.

The analysis of the individual warming trends in the models measured by the ZSG slope and the ratio of events shows that La Niña-like warming models show stronger decreases of EP events the stronger the differentiated zonal SST warming is, but this relationship does not apply to the El Niño-like warming models (Figs. $8 \mathrm{j}-1$ ). Neither of these relationships are statistically significant. Thus, the mean-state response to warming is not a reliable predictor of future $\mathrm{CP}$ or $\mathrm{EP}$ event frequency change.

In addition to mean-state responses to warming, decadal-scale variability has been suggested as a possible cause of frequency changes in the observations $(\mathrm{Hu}$ et al. 2013; Guan and McPhaden 2016; Lübbecke and McPhaden 2014). We next investigate if these changes could be related to differences in decadal-scale variability during PDV positive and negative phases. Figure 9a shows a summary of the changes simulated by the CMIP models in comparison to the instrumental record (appendix B) and the preindustrial control simulations and future simulations. This time, all models are sorted by their strength of change showing the strongest decreases of CP/EP ratio (Fig. 9, left) to strongest increases (Fig. 9, right). Again, most of the El Niño-like warming models' group toward less CP events and more EP events, related to a future decrease of CP/EP ratio (Fig. 9, left). Interestingly, most of the models indicating future increases of CP/EP ratio are CMIP6 models.

By focusing on positive and negative phase of PDV, we investigate if differences and changes of El Niño frequency arise from low-frequency phases of the Pacific mean state such as El Niño-like or La Niña-like decadal phases. In the instrumental record, both EP and CP 
events occur more frequently during positive PDV phases (Fig. 9b, HadISST). The majority of models show that both El Niño types occur more frequently during PDV positive phase $(\mathrm{PDV}+)$ than its negative phase (Fig. 9b) and this is more pronounced for $\mathrm{CP}$ events. The vast majority of simulated $\mathrm{CP}$ events occur during PDV positive phases, whereas EP events can occur more regularly during both PDV phases. Models that simulate strong future changes of $\mathrm{CP} / \mathrm{EP}$ ratio show a trend for an even greater proportion of $\mathrm{CP}$ events in the positive PDV phase. Figure 9c shows how the event frequency changes from preindustrial control and RCP8.5/SSP58.5 during PDV positive and negative phases. Models that project decreases of $\mathrm{CP} / \mathrm{EP}$ show a general reduction of CP events during both phases of PDV. A similar result applies to models that show increasing $\mathrm{CP} / \mathrm{EP}$, for which all models show strongest future decreases of EP frequency during positive PDV but not necessarily during the negative PDV phase.

\section{El Niño intensity in CMIP models}

We next investigate the range of simulated El Niño event intensities and compare CMIP model results with the instrumental record and reconstruction. The El Niño event intensities are directly derived from the Niño-3 and Niño-4 indices as the maximum SSTA during an El Niño event in DJF. Figures 10a and 10f show the interquartile range of event intensities prior to 1980 . Compared to the range of reconstructed event amplitudes, recent $\mathrm{CP}$ events have not increased in intensity (Fig. 10a), whereas the three most recent EP events appear unusual (Fig. 10g). The range of El Niño events from the CMIP preindustrial control simulations shows large variations in CP (Fig. 10b) and EP event intensity (Fig. 10g). There is no pattern between the simulated range of variability and model skill according to our ranking. The GISS-E2-H model shows the strongest variability of $\mathrm{CP}$ event intensity, whereas the FIO-ESM model shows the least variations for both EP and CP events. The majority of models shows stronger intensities of $\mathrm{CP}$ events during PDV positive phases than negative phases (Fig. 10d). Interestingly, five models (BNU-ESM, IPSL-CM5B-LR, FGOALS-g2, GISS-E2-H, and BCCCSM2-MR) show opposing characteristics of more intense $\mathrm{CP}$ events during PDV negative phases. A future decrease of CP event intensity is mainly determined by the decrease of CP events during the positive PDV phase (Fig. 10e). In contrast, models that simulate more intense CP events in future projections show an intensification during both PDV phases (Fig. 10e). A decrease of CP intensity is, therefore, mainly driven by less intense $\mathrm{CP}$ events during positive PDV phases.
The most recent observed EP event intensities mostly exceed the interquartile range of variability represented by the preindustrial control simulations (Fig. 10f). Most of the preindustrial control simulations do not incorporate these strong intensities within their interquartile range (Fig. 10g). The exception are the models: CESM1BGC, MRI-ESM2.0, CMCC-CM, and MIROC6, which show large variations of EP event intensity that can exceed the recent EP event intensities.

The intensity of EP events is less determined by the PDV phase than for CP events. A similar number of models simulate stronger and weaker EP events during positive and negative PDV phases (Fig. 10i). In particular, better performing models agree on this behavior and simulate intense EP events in both PDV phases. A comparison with the RCP8.5 and SSP5-8.5 simulations shows no model agreement on the sign of change in terms of event intensity (Fig. 10k). Models showing more intense EP events in a future climate are mainly driven by an intensification of EP events during the negative PDV phase (11 out of 13 models) but can show a decrease in both phases.

Further, we test the hypothesis that models with a larger amount of warming may show stronger EP or CP event intensity changes. Neither for CP nor for EP El Niño are event intensity changes directly related to the global temperature increase in the models.

Similarly to the frequency changes, we also group the models by the different mean-state changes. Most La Niña-like warming models show a tendency toward stronger CP El Niño events in a future climate (Fig. 10c). El Niño-like warming models on the other hand show no clear pattern and differ on the sign of change. The intensity changes of EP events are similarly diverse (Fig. 10h). Although the numbers of La Niña- and El Niño-like warming models in our sample is small, we argue that the spatial pattern of SST change does not appear to be the main explanation for model disagreement on projected changes in CP and EP El Niño event intensity.

Overall, there is no clear model agreement on a future trend toward more intense El Niño events as observed in recent decades (Fig. 10f). A similar number of models project an increase of intense EP and CP events as project a decrease. The vast majority of models simulate more intense CP events during PDV positive phases. The intensity of EP events is less restricted to a certain phase of PDV and shows models with more intense EP events during positive and negative PDV phases. Future changes of EP event intensity are mainly driven by changes in intensity during negative PDV phases, whereas CP event intensity is driven by changes during both PDV phases. 
CP El Niño

Variability in control simulations

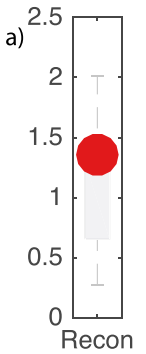

2.5

b)

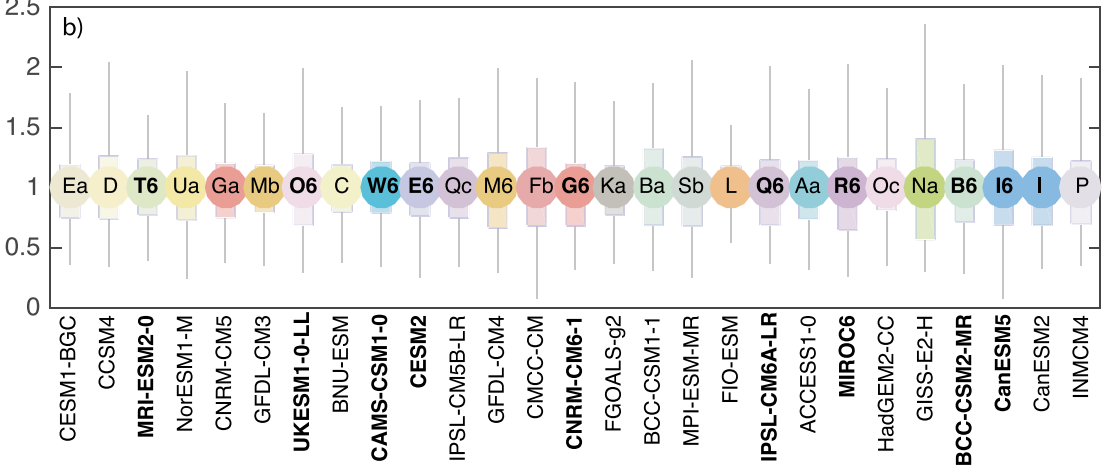

Mean state change

d)
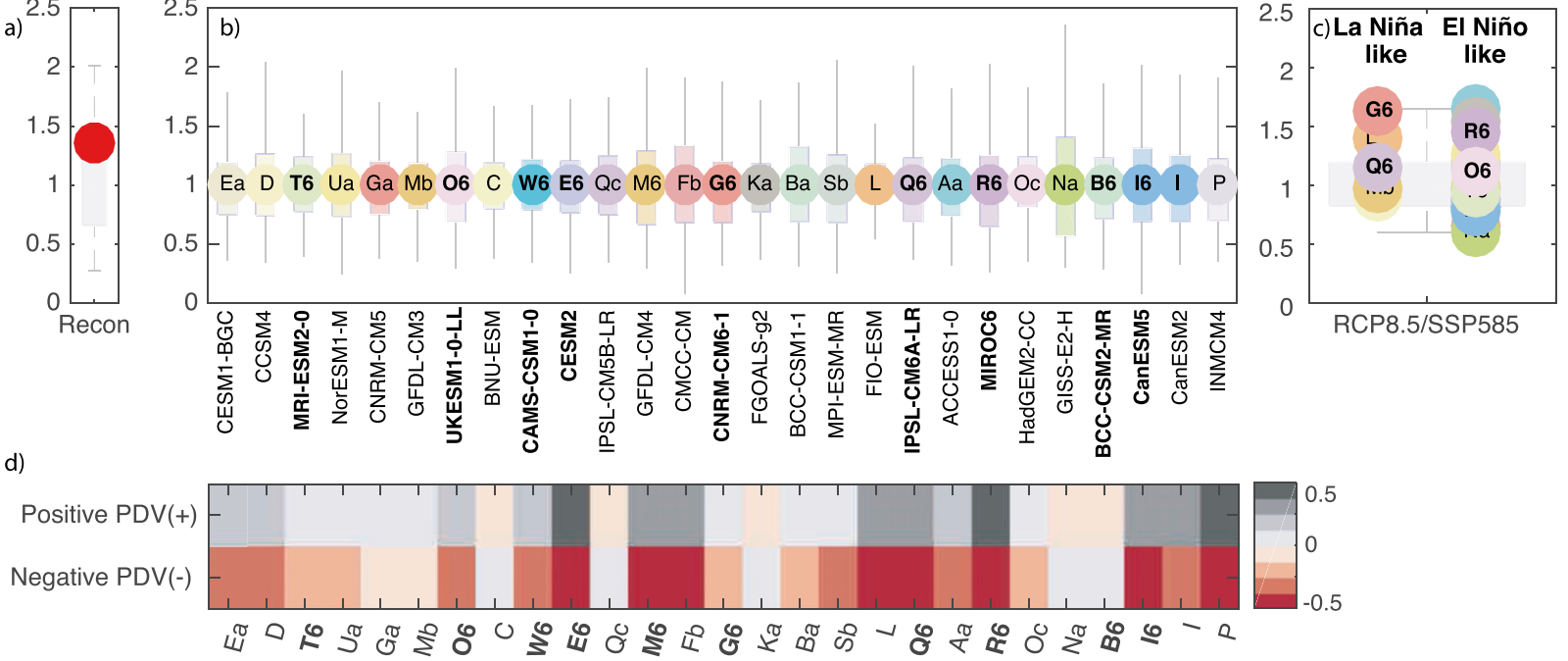

e)

Future decrease CP intensity Future increase CP intensity

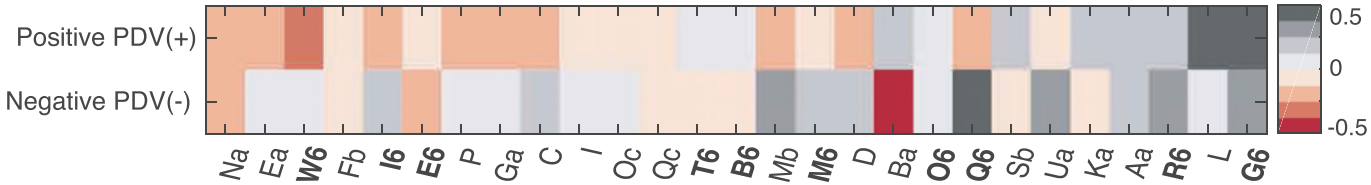

EP EI Niño

Variability in control simulations

Mean state change
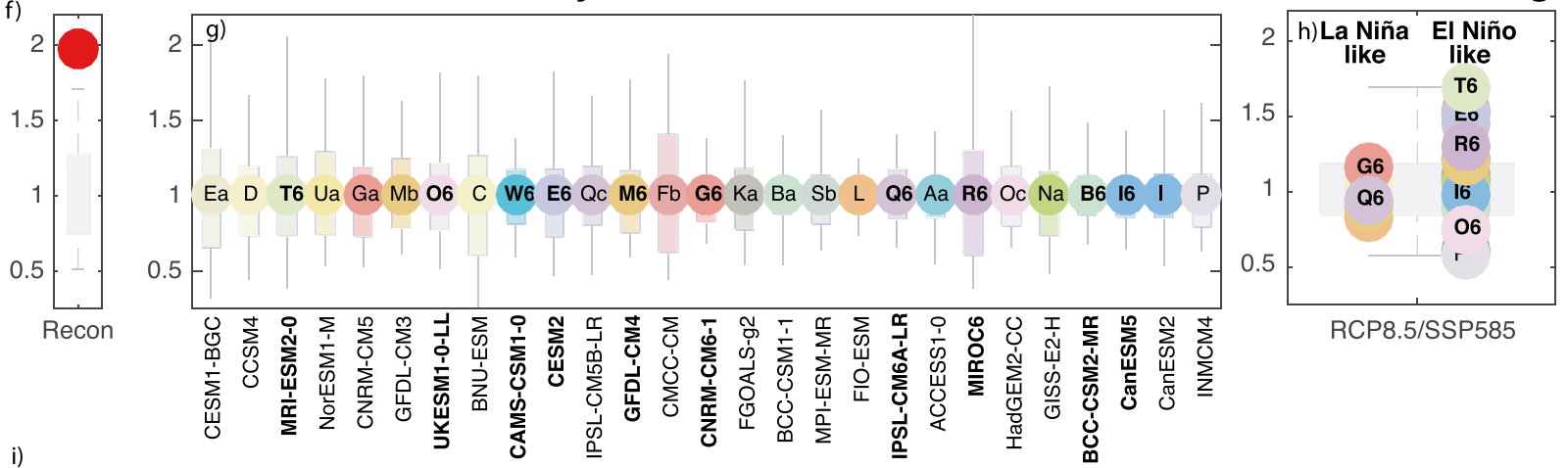

RCP8.5/SSP585

i)
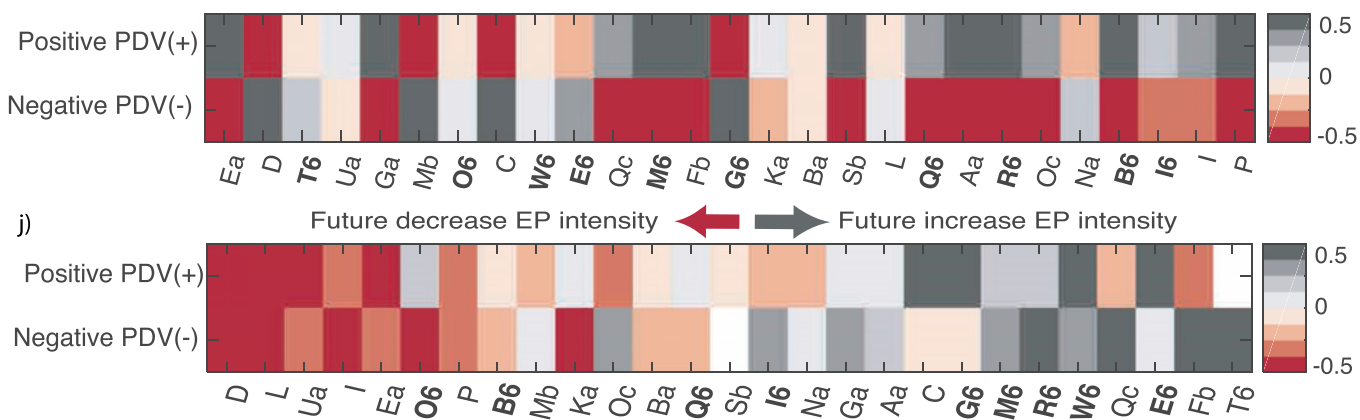

FIG. 10. El Niño intensity of (a)-(e) CP El Niño events and (f)-(j) EP El Niño events derived from the reconstructed 400-yr reference period prior to 1980 (boxplot) and recent observation (red dot) in (a) and (e), and from CMIP5 and CMIP6 (bold) preindustrial control simulations in (b) and (g) relative to different reference periods. Average CP in (c) and EP in (h) El Niño intensity in the RCP8.5/SSP5-8.5 scenario grouped by models with a La Niña-like warming trend and El Niño-like warming trend in (d) and (i). Difference of El Niño intensity during positive and negative PDV periods in the control simulations relative to the individual model event frequency derived from the preindustrial control simulations in (e) and (j) sorted according to the model ranking. Changes of El Niño intensity as the difference of El Niño intensity during positive and negative PDV phases derived from the preindustrial control simulations and the RCP8.5/SSP8-5.8 simulations in (e) and (j), sorted from strongest declines (left) to largest increases (right) in terms overall change. 


\section{Discussion}

Motivated by recent observations of a trend toward more CP and stronger EP events, we have used climate model simulations from CMIP5 and CMIP6 to investigate how different warming patterns, amounts of mean warming, and Pacific decadal variability affect El Niño diversity.

We find no overall model agreement on the projected sign of frequency or intensity changes of EP and CP El Niño events in either CMIP5 or CMIP6 models. A similar number of models indicate positive changes as negative changes in El Niño frequency and intensity. The lack of intermodel agreement of projected El Niño changes persists, even when considering a subset of better performing models. Although only based on 10 new models from CMIP6 there is preliminary evidence that more CMIP6 models show an increase in the ratio of El Niño event frequencies $(\mathrm{CP} / \mathrm{EP})$ compared to the previous generation of CMIP5 models.

We find that the rate of temperature increase as a proxy for the warming rate of a model is not a predictor of projected El Niño changes. Models that simulate greater future warming do not show consistently stronger changes nor agreement on the sign of changes compared to models that simulate less future warming. However, models with a La Niña-like mean-state warming show a tendency toward more EP and less $\mathrm{CP}$ events as a response to anthropogenic forcing. The robustness of this result is limited by the fact that only 5 models show a La Niña-like mean-state response to warming. Future research could investigate the La Niña-like warming models in more detail and make use of a larger set of CMIP6 models to reduce uncertainty associated with the current small sample of La Niña-like warming models.

In addition to mean-state changes, we find that responses to low-frequency variability such as the PDV can potentially contribute to frequency changes of El Niño. All models simulate an increase in the number of EP and CP El Niño events during PDV positive phases and a reduction during PDV negative phases. The projected change in El Niño event frequency may depend on the background PDV state for the periods considered (Dewitte et al. 2007). The majority of models simulate stronger $\mathrm{CP}$ events during the positive phase of PDV than its negative phase. Interestingly, the intensity of EP El Niño events is less determined by low-frequency phases of the PDV. We conclude that the PDV is more important for future frequency changes than intensity changes of El Niño events.

Overall, our analysis of El Niño types in the CMIP models shows a lack of intermodel agreement of pro- jected El Niño changes, consistent with previous studies (Bellenger et al. 2014; Chen et al. 2017; Kim and Yu 2012). Although greatest model agreement was found for the spatial pattern of EP and CP events (Figs. 5 and 6), most of the models show an overly westward extent of SSTA pattern along the equator (Taschetto et al. 2014; L'Heureux et al. 2012). Seager et al. (2019) argues that coupled models misrepresent the response of the tropical Pacific to anthropogenic warming due to this cold tongue bias. Although our model evaluation approach excluded a number of models with an extensive cold tongue bias, further analysis could focus on only the best ranked models to avoid biases that potentially alter El Niño properties (Brown et al. 2013; Graham et al. 2017). In addition, correctly simulated SST variability can be a driven by the wrong dynamics. For example, Bayr et al. (2019) has shown that too-weak feedbacks in CMIP5 models can lead to an error compensation between the wind-SST feedback and the heat-flux feedback that results in realistic simulated SST variability for the wrong physical reasoning. Possible remaining biases such as thermocline variations and zonal advection could also explain why overall EP El Niño SST patterns are better captured by the simulations than the CP El Niño patterns.

The role of biases can also play a crucial role for the identification of El Niño events itself. The classification approach provides a reliable framework to identify the different types of El Niño events in climate model simulations but also relies on the assumption that models adequately represent ENSO variability. Alternative approaches adapt to the model biases by following the location of anomaly centers as done by Cai et al. (2018). This bears the risk of including weak or false events simulated by models that do not adequately represent ENSO variability and the physical processes responsible for ENSO diversity. A comparison of results based on such adaptive approaches versus the nonadaptive approach used in this study could be valuable. We also argue that the objective method applied in this study to identify and classify El Niño events based on their observed spatial and temporal characteristics enables a direct comparison of palaeoreconstructions, instrumental records, and climate models.

Furthermore, our study has only considered surface conditions in the tropical Pacific. Coupled ocean and atmosphere processes including equatorial wind anomalies (Chen et al. 2015), zonal advection (Yeh et al. 2009), and shifts of convection centers (Stuecker et al. 2013) are known to be important to El Niño diversity (Hu and Fedorov 2018). Future work could include atmospheric circulation and oceanic processes and variables to reduce uncertainties. 
The response of El Niño diversity to increasing greenhouse gases remains uncertain based on the lack of model agreement. Improvements in model biases and representation of El Niño diversity from previous CMIP phases (AchutaRao and Sperber 2006; Bellenger et al. 2014) may be promising, but based on the available CMIP6 models considered in this study, no dramatic improvement in the representation of ENSO properties is evident. Some CMIP6 models examined exhibit persistent biases in seasonality and overestimate SST variability, although the new models show no secondary peak in SST variability in the zonal direction based on the small sample of available models.

The role of differentiated zonal SST warming was found to be particularly important for frequency changes. La Niña-like warming models project fewer CP events and more EP events in the future. The reverse for $\mathrm{El}$ Niño-like warming models is less clear. Therefore, only models with an El Niño-like warming response to anthropogenic warming appear to be consistent with the recent increase of observed CP frequency. In light of current debates on El Niño-like warming or La Niña-like warming trends (Lian et al. 2018; Seager et al. 2019) and based on this study, increased CP events would be expected to be accompanied by a weakening of the tropical zonal SST gradient consistent with some previous studies (Vecchi et al. 2006). Nevertheless, a high degree of internal variability and a late emergence of mean-state changes in terms of SST trends toward the end of the simulation period may explain differences between El Niño-like models (Coats and Karnauskas 2017).

The impact of decadal-scale background-state changes is found to influence both intensity and frequency changes to a large degree. Despite the known shortcomings of climate models to adequately reflect lowfrequency variability in their simulations (Henley et al. 2017), we found ENSO multidecadal variability to be closely linked to the occurrence frequency of El Niño events. The number of EP and CP El Niño events is higher during PDV positive phases (appendix B) along with the intensity of $\mathrm{CP}$ events. Interestingly the intensity of EP events is less defined by the decadal background state according to the CMIP models. Future work will need to address the interplay of mean-state warming patterns and decadal-scale changes in El Niño diversity in greater detail and aim to separate internal variability and responses to external forcing such volcanic forcing, which can be linked to ENSO events.

Acknowledgments. We thank Eun-Pa Lim and Kavina Dayal for their helpful comments on earlier versions of the manuscript. We acknowledge the World Climate Research Programme's Working Group on Coupled
Modelling, which is responsible for CMIP, and we thank the climate modelling groups (listed in Table A1 of this paper) for producing and making available their model outputs. Josephine Brown and Benjamin Henley are affiliated ARC Centre of Excellence for Climate Extremes. David Karoly is supported through funding from the Earth Systems and Climate Change Hub of the Australian Government's National Environmental Science Program. Benjamin Henley receives funds from an Australian Research Council Linkage Project (LP150100062) with Melbourne Water, the Victorian Department of Environment, Land, Water and Planning, and the Australian Bureau of Meteorology.

\section{APPENDIX A}

\section{Seasonal Phase Locking}

We evaluate the CMIP5 and CMIP6 models (listed in Table A1) for a correct representation of ENSO's seasonal phase locking. The strongest variability of Niño-3 and Niño-4, measured by the standard deviation (StdDEV) during austral spring and summer (DJF), has been used as a proxy of seasonal phase locking. In addition, minimum variability during austral autumn (AMJ) can be an important characteristic of the seasonality of ENSO. We therefore follow the approach by Bellenger et al. (2014) adapted by Wengel (2018) and calculate the PLI for Niño-3 and Niño indices:

$$
\mathrm{PLI}=\frac{\operatorname{StdDEV}\left(\mathrm{SSTA}_{\mathrm{Niño}}\right)_{\mathrm{DJF}}}{\operatorname{StdDEV}\left(\operatorname{SSTA}_{\mathrm{Niño}}\right)_{\mathrm{AMJ}}} .
$$

Here we show a different method to quantify the seasonal phase locking in models. Figure A1 shows the PLI for the Niño-4 (Fig. A1a) and Niño-3 (Fig. A1b) indices. Compared to the observations most models show a weaker phase locking than observed. Extreme strong and weak seasonal phase locking in the Niño-3 region is found in CMCC-CMS, CSIRO-Mk3.6-0, IPSL-CM5AMR, CanESM5, and IPSL-CM6A-LR. Similar to the maximum variability approach, these models have not been included in further analysis.

\section{APPENDIX B}

\section{Pacific Decadal Variability}

The recent tendency toward more CP El Niño events has been suggested to be linked to a shift of PDV (Hu et al. 2013; Guan and McPhaden 2016; Lübbecke and McPhaden 2014). Here we show the occurrence of EP 
TABLE A1. Overview CMIP5 and CMIP6 models. Available control simulations from the CMIP project that are considered in this study.

\begin{tabular}{|c|c|c|c|c|}
\hline Abbr. & Model & Tier & Center & Reference \\
\hline Aa & ACCESS1.0 & ACC & $\begin{array}{l}\text { Commonwealth Scientific and Industrial } \\
\text { Research Organization and Bureau of } \\
\text { Meteorology, Australia }\end{array}$ & Bi et al. (2013) \\
\hline $\mathrm{Ab}$ & ACCESS1.3 & ACC & $\begin{array}{l}\text { Commonwealth Scientific and Industrial } \\
\text { Research Organization and Bureau of } \\
\text { Meteorology, Australia }\end{array}$ & Bi et al. (2013) \\
\hline $\mathrm{Bb}$ & BCC-CSM1.1-M & $\mathrm{BCC}$ & $\begin{array}{l}\text { Beijing Climate Center, China } \\
\text { Meteorological Administration, China }\end{array}$ & Wu et al. (2008) \\
\hline $\mathrm{Ba}$ & BCC-CSM1.1 & $\mathrm{BCC}$ & $\begin{array}{l}\text { Beijing Climate Center, China } \\
\text { Meteorological Administration, China }\end{array}$ & Wu et al. (2008) \\
\hline $\mathrm{C}$ & BNU-ESM & BNU & Beijing Normal University, China & Ji et al. (2014) \\
\hline $\mathrm{D}$ & CCSM4 & CCS & $\begin{array}{l}\text { National Center for Atmospheric } \\
\text { Research (NCAR), United States }\end{array}$ & Gent et al. (2011) \\
\hline $\mathrm{Ea}$ & CESM1-BGC & CES & $\begin{array}{l}\text { National Science Foundation/ } \\
\text { Department of Energy NCAR, United } \\
\text { States }\end{array}$ & Long et al. (2013) \\
\hline $\mathrm{Eb}$ & CESM1-CAM5 & CES & $\begin{array}{l}\text { National Science Foundation/ } \\
\text { Department of Energy NCAR, United } \\
\text { States }\end{array}$ & Meehl et al. (2013) \\
\hline $\mathrm{Ed}$ & CESM1-FASTCHEM & CES & $\begin{array}{l}\text { National Science Foundation/ } \\
\text { Department of Energy NCAR, United } \\
\text { States }\end{array}$ & Meehl et al. (2013) \\
\hline $\mathrm{Ee}$ & CESM1-WACCM & CES & $\begin{array}{l}\text { National Science Foundation/ } \\
\text { Department of Energy NCAR, United } \\
\text { States }\end{array}$ & Meehl et al. (2013) \\
\hline $\mathrm{Fc}$ & CMCC-CMS & $\mathrm{CMC}$ & $\begin{array}{l}\text { Centro Euro-Mediterraneo per i } \\
\text { Cambiamenti, Italy }\end{array}$ & Fogli et al. (2009) \\
\hline $\mathrm{Fb}$ & $\mathrm{CMCC}-\mathrm{CM}$ & $\mathrm{CMC}$ & $\begin{array}{l}\text { Centro Euro-Mediterraneo per i } \\
\text { Cambiamenti, Italy }\end{array}$ & Fogli et al. (2009) \\
\hline $\mathrm{Ga}$ & CNRM-CM5 & $\mathrm{CNR}$ & $\begin{array}{l}\text { Centre National de Recherches } \\
\text { Meteorologiques, Météo-France, } \\
\text { France }\end{array}$ & Voldoire et al. (2012) \\
\hline $\mathrm{Ha}$ & CSIRO-Mk3.6-0 & CSI & $\begin{array}{l}\text { Commonwealth Scientific and Industrial } \\
\text { Research Organization, Australia }\end{array}$ & Rotstayn et al. (2012) \\
\hline $\mathrm{Hb}$ & CSIRO-Mk3L-1.2 & CSI & $\begin{array}{l}\text { Commonwealth Scientific and Industrial } \\
\text { Research Organization, Australia }\end{array}$ & Rotstayn et al. (2012) \\
\hline I & CanESM2 & Can & $\begin{array}{l}\text { Canadian Centre for Climate Modeling } \\
\text { and Analysis, Canada }\end{array}$ & Arora et al. (2011) \\
\hline $\mathrm{Ka}$ & FGOALS-g2 & FGO & $\begin{array}{l}\text { Institute of Atmospheric Physics, Chinese } \\
\text { Academy of Sciences, China }\end{array}$ & Bao et al. (2013) \\
\hline $\mathrm{Kb}$ & FGOALS-s2 & FGO & $\begin{array}{l}\text { Institute of Atmospheric Physics, Chinese } \\
\text { Academy of Sciences, China }\end{array}$ & Bao et al. (2013) \\
\hline $\mathrm{L}$ & FIO-ESM & FIO & $\begin{array}{l}\text { First Institute of Oceanography-Earth } \\
\text { System Model, China }\end{array}$ & Qiao et al. (2013) \\
\hline $\mathrm{Mb}$ & GFDL-CM3 & GFD & $\begin{array}{l}\text { Geophysical Fluid Dynamics Laboratory, } \\
\text { United States }\end{array}$ & Donner et al. (2011) \\
\hline Mc & GFDL-ESM2G & GFD & $\begin{array}{l}\text { Geophysical Fluid Dynamics Laboratory, } \\
\text { United States }\end{array}$ & Dunne et al. (2012) \\
\hline Md & GFDL-ESM2M & GFD & $\begin{array}{l}\text { Geophysical Fluid Dynamics Laboratory, } \\
\text { United States }\end{array}$ & Dunne et al. (2012) \\
\hline $\mathrm{Na}$ & GISS-E2-H & GIS & $\begin{array}{l}\text { Goddard Institute for Space Studies, } \\
\text { United States }\end{array}$ & Miller et al. (2014) \\
\hline $\mathrm{Nc}$ & GISS-E2-R & GIS & $\begin{array}{l}\text { Goddard Institute for Space Studies, } \\
\text { United States }\end{array}$ & Miller et al. (2014) \\
\hline $\mathrm{Nc}$ & GISS-E2-R & GIS & $\begin{array}{l}\text { Goddard Institute for Space Studies, } \\
\text { United States }\end{array}$ & Miller et al. (2014) \\
\hline $\mathrm{Nc}$ & GISS-E2-R & GIS & $\begin{array}{l}\text { Goddard Institute for Space Studies, } \\
\text { United States }\end{array}$ & Miller et al. (2014) \\
\hline
\end{tabular}


TABLE A1. (Continued)

\begin{tabular}{|c|c|c|c|c|}
\hline Abbr. & Model & Tier & Center & Reference \\
\hline Oc & HadGEM2-CC & Had & $\begin{array}{l}\text { Met Office Hadley Centre, United } \\
\text { Kingdom }\end{array}$ & Collins et al. (2011) \\
\hline Od & HadGEM2-ES & Had & $\begin{array}{l}\text { Met Office Hadley Centre, United } \\
\text { Kingdom }\end{array}$ & Collins et al. (2011) \\
\hline$P$ & INMCM4 & INM & $\begin{array}{l}\text { Institute for Numerical Mathematics, } \\
\text { Russia }\end{array}$ & Volodin et al. (2010) \\
\hline Qa & IPSL-CM5A-LR & IPS & Institut Pierre-Simon Laplace, France & Dufresne et al. (2013) \\
\hline $\mathrm{Qb}$ & IPSL-CM5A-MR & IPS & Institut Pierre-Simon Laplace, France & Dufresne et al. (2013) \\
\hline Qc & IPSL-CM5B-LR & IPS & Institut Pierre-Simon Laplace, France & Dufresne et al. (2013) \\
\hline $\mathrm{Ra}$ & MIROC-ESM & MIR & $\begin{array}{l}\text { Atmosphere and Ocean Research } \\
\text { Institute (AORI), National Institute for } \\
\text { Environmental Studies (NIES), Japan } \\
\text { Agency for Marine-Earth Science and } \\
\text { Technology (JAMSTEC), Japan }\end{array}$ & Watanabe et al. (2011) \\
\hline $\mathrm{Rc}$ & MIROC4h & MIR & AORI, NIES, JAMSTEC, Japan & Sakamoto et al. (2012) \\
\hline $\mathrm{Rd}$ & MIROC5 & MIR & AORI, NIES, JAMSTEC, Japan & Watanabe et al. (2010) \\
\hline $\mathrm{Sa}$ & MPI-ESM-LR & MPI & $\begin{array}{l}\text { Max Planck Institute for Meteorology, } \\
\text { Germany }\end{array}$ & Giorgetta et al. (2013) \\
\hline $\mathrm{Sb}$ & MPI-ESM-MR & MPI & $\begin{array}{l}\text { Max Planck Institute for Meteorology, } \\
\text { Germany }\end{array}$ & Giorgetta et al. (2013) \\
\hline $\mathrm{Sc}$ & MPI-ESM-P & MPI & $\begin{array}{l}\text { Max Planck Institute for Meteorology, } \\
\text { Germany }\end{array}$ & Giorgetta et al. (2013) \\
\hline $\mathrm{Ta}$ & MRI-CGCM3 & MRI & Meteorological Research Institute, Japan & Yukimoto et al. (2012) \\
\hline $\mathrm{Ub}$ & NorESM1-ME & Nor & Norwegian Climate Centre, Norway & Bentsen et al. (2013) \\
\hline $\mathrm{Ua}$ & NorESM1-M & Nor & Norwegian Climate Centre, Norway & Bentsen et al. (2013) \\
\hline B6 & BCC-CSM2-MR & $\mathrm{BCC}$ & $\begin{array}{l}\text { Beijing Climate Center, China } \\
\text { Meteorological Administration, China }\end{array}$ & Wu et al. (2008) \\
\hline W6 & CAMS-CSM1.0 & CAM & $\begin{array}{l}\text { Max Planck Institute for Meteorology, } \\
\text { Germany }\end{array}$ & Roeckner et al. (2003) \\
\hline E6 & CESM2 & CES & $\begin{array}{l}\text { National Science Foundation/ } \\
\text { Department of Energy, NCAR, United } \\
\text { States }\end{array}$ & Meehl et al. (2013) \\
\hline G6 & CNRM-CM6.1 & $\mathrm{CNR}$ & $\begin{array}{l}\text { Centre National de Recherches } \\
\text { Meteorologiques, Météo-France, } \\
\text { France }\end{array}$ & Voldoire et al. (2012) \\
\hline I6 & CanESM5 & Can & $\begin{array}{l}\text { Canadian Centre for Climate Modeling } \\
\text { and Analysis, Canada }\end{array}$ & Arora et al. (2011) \\
\hline M6 & GFDL-CM4 & GFD & $\begin{array}{l}\text { Geophysical Fluid Dynamics Laboratory, } \\
\text { United States }\end{array}$ & Dunne et al. (2012) \\
\hline Q6 & IPSL-CM6A-LR & IPS & Institut Pierre-Simon Laplace, France & Dufresne et al. (2013) \\
\hline R6 & MIROC6 & MIR & AORI, NIES, JAMSTEC, Japan & Watanabe et al. (2011) \\
\hline T6 & MRI-ESM2.0 & MRI & Meteorological Research Institute, Japan & Yukimoto et al. (2012) \\
\hline O6 & UKESM1.0-LL & UKE & $\begin{array}{l}\text { Met Office Hadley Centre, United } \\
\text { Kingdom }\end{array}$ & Collins et al. (2011) \\
\hline
\end{tabular}

and CP El Niño events and occurrence frequency in conjunction with the different phases of PDV (Fig. B1). As most records of El Niño variability often cover the later part of the instrumental period (starting in the 1950s and 1970s), only a limited number of PDV phases have been assessed.

We show details on past El Niño event occurrence and occurrence frequencies during different observed PDV phases following the events identified in Freund et al. (2019). Similar to the instrumental studies, the strongest increase of $\mathrm{CP}$ events has occurred during a PDV negative phase after the year 1999. Nevertheless, on average both EP and CP events occur more often during PDV positive phases. At the same time, the frequency of CP events has started to increase from the 1980s during a positive PDV phase and continued to increase during the following negative PDV phase.

However, it should be noted that both the estimate of PDV based on the TPI index (Henley et al. 2015) and El Niño events are derived from the monthly sea surface temperatures HadISST v.1.1 (Rayner et al. 2003) dataset, which could be less reliable before 1920 . 

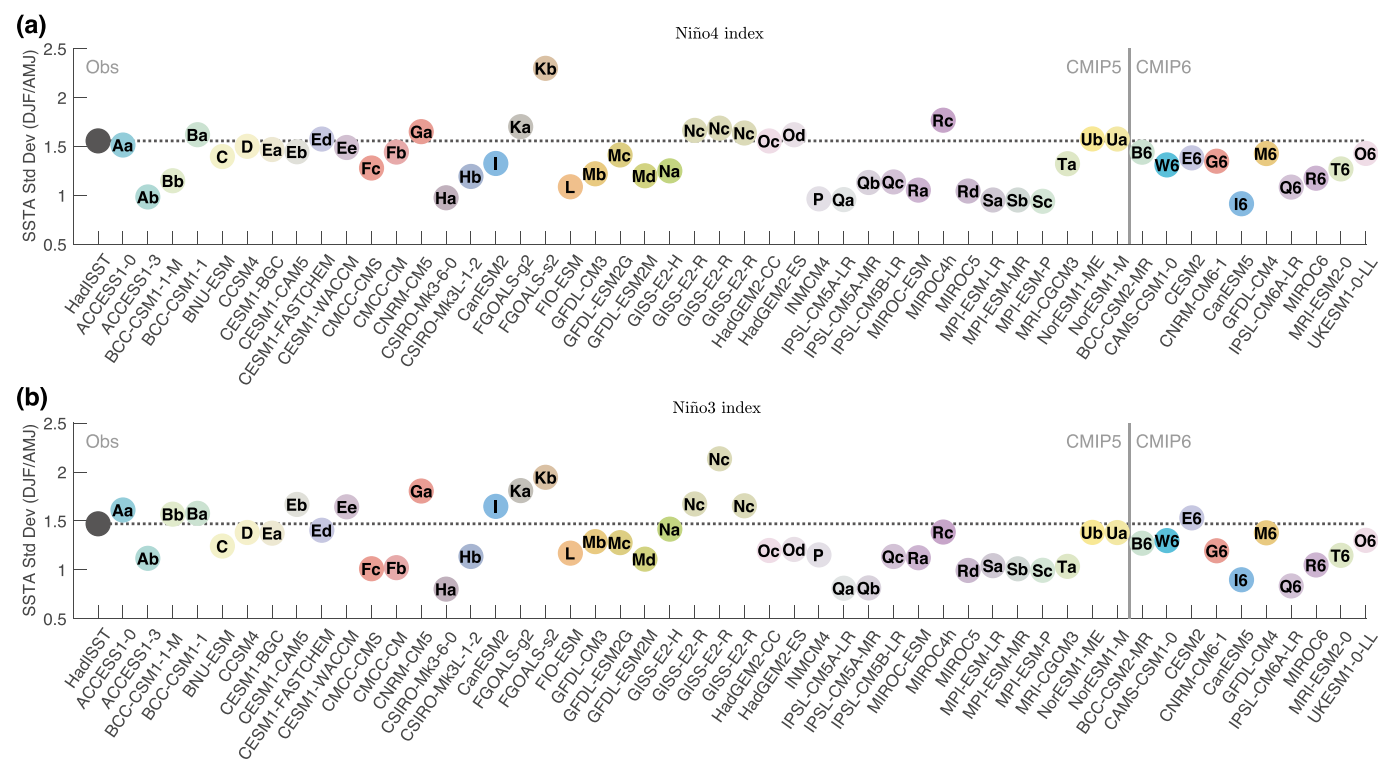

FIG. A1. Seasonal phase locking. PLI based on the (a) Niño-4 index and (b) Niño-3 index for all CMIP5 and CMIP6 models compared to the observed (HadISST: dashed line).

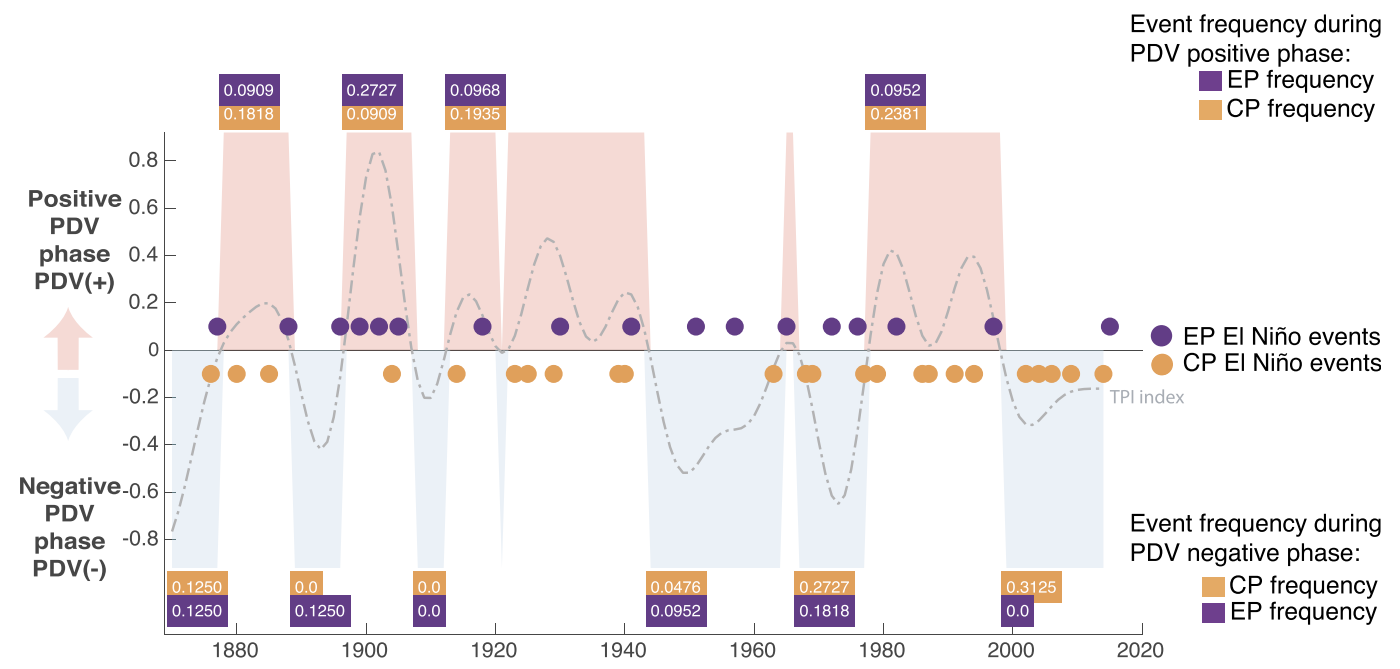

FIG. B1. Occurrence of different types of El Niño. Observed occurrence of EP and CP El Niño events according to Freund et al. (2019) during the instrumental period (1870-2018). Insets show the event occurrence frequencies during PDV positive phases (upper inset) and PDV positive phases (lower inset) based on shaded observed periods of PDV based on TPI index (Henley et al. 2015).

\section{REFERENCES}

AchutaRao, K., and K. R. Sperber, 2006: ENSO simulation in coupled ocean-atmosphere models: Are the current models better? Climate Dyn., 27, 1-15, https://doi.org/10.1007/s00382-006-0119-7.

An, S.-I., J.-W. Kim, S.-H. Im, B.-M. Kim, and J.-H. Park, 2011: Recent and future sea surface temperature trends in tropical Pacific warm pool and cold tongue regions. Climate Dyn., 39, 1373-1383, https://doi.org/10.1007/s00382-011-1129-7.
Anderson, W. B., R. Seager, W. Baethgen, M. Cane, and L. You, 2019: Synchronous crop failures and climate-forced production variability. Sci. $A d v ., 5$, eaaw1976, https://doi.org/10.1126/ sciadv.aaw1976.

Anyamba, A., and Coauthors, 2019: Global disease outbreaks associated with the 2015-2016 El Niño event. Sci. Rep., 9, 1930, https://doi.org/10.1038/s41598-018-38034-z.

Arora, V. K., and Coauthors, 2011: Carbon emission limits required to satisfy future representative concentration pathways 
of greenhouse gases. Geophys. Res. Lett., 38, L05805, https:// doi.org/10.1029/2010gl046270.

Ashok, K., S. K. Behera, S. A. Rao, H. Weng, and T. Yamagata, 2007: El Niño Modoki and its possible teleconnection. J. Geophys. Res., 112, C11007, https://doi.org/10.1029/2006jc003798.

Bao, Q., and Coauthors, 2013: The Flexible Global OceanAtmosphere-Land System Model, Spectral version 2: FGOALS-s2. Adv. Atmos. Sci., 30, 561-576, https://doi.org/ 10.1007/s00376-012-2113-9.

Bayr, T., D. Dommenget, T. Martin, and S. B. Power, 2014: The eastward shift of the Walker circulation in response to global warming and its relationship to ENSO variability. Climate Dyn., 43, 2747-2763, https://doi.org/10.1007/s00382-014-2091-y.

_, M. Latif, D. Dommenget, C. Wengel, J. Harlaß, and W. Park, 2017: Mean-state dependence of ENSO atmospheric feedbacks in climate models. Climate Dyn., 50, 3171-3194, https:// doi.org/10.1007/s00382-017-3799-2.

-, C. Wengel, M. Latif, D. Dommenget, J. Lübbecke, and W. Park, 2019: Error compensation of ENSO atmospheric feedbacks in climate models and its influence on simulated ENSO dynamics. Climate Dyn., 53, 155-172, https://doi.org/ 10.1007/s00382-018-4575-7.

Bellenger, H., E. Guilyardi, J. Leloup, M. Lengaigne, and J. Vialard, 2014: ENSO representation in climate models: From CMIP3 to CMIP5. Climate Dyn., 42, 1999-2018, https://doi.org/10.1007/ s00382-013-1783-z.

Bentsen, M., and Coauthors, 2013: The Norwegian Earth System Model, NorESM1-M-Part I: Description and basic evaluation of the physical climate. Geosci. Model Dev., 6, 687-720, https://doi.org/10.5194/gmd-6-687-2013.

Bi, D., and Coauthors, 2013: The ACCESS coupled model: Description, control climate and evaluation. Aust. Meteor. Oceanogr. J., 63, 41-64, https://doi.org/10.22499/2.6301.004.

Brown, J. N., C. Langlais, and C. Maes, 2013: Zonal structure and variability of the western Pacific dynamic warm pool edge in CMIP5. Climate Dyn., 42, 3061-3076, https://doi.org/10.1007/ s00382-013-1931-5.

, - — , and A. Sen Gupta, 2015: Projected sea surface temperature changes in the equatorial Pacific relative to the warm pool edge. Deep-Sea Res. II, 113, 47-58, https://doi.org/ 10.1016/j.dsr2.2014.10.022.

Cai, W., and Coauthors, 2018: Increased variability of eastern Pacific El Niño under greenhouse warming. Nature, 564, 201206, https://doi.org/10.1038/s41586-018-0776-9.

Cane, M., A. Clement, A. Kaplan, Y. Kushnir, D. Pozdnyakov, R. Seager, S. Zebiak, and R. Murtugudde, 1997: Twentiethcentury sea surface temperature trends. Science, 275, 957-960, https://doi.org/10.1126/science.275.5302.957.

Capotondi, A., and Coauthors, 2015: Understanding ENSO diversity. Bull. Amer. Meteor. Soc., 96, 921-938, https://doi.org/ 10.1175/BAMS-D-13-00117.1.

Cashin, P., K. Mohaddes, and M. Raissi, 2017: Fair weather or foul? The macroeconomic effects of El Niño. J. Int. Econ., 106, $37-$ 54, https://doi.org/10.1016/j.jinteco.2017.01.010.

Chang, P., B. Wang, T. Li, and L. Ji, 1994: Interactions between the seasonal cycle and the Southern Oscillation-Frequency entrainment and chaos in a coupled ocean-atmosphere model. Geophys. Res. Lett., 21, 2817-2820, https://doi.org/10.1029/ 94GL02759.

Chen, C., M. A. Cane, A. T. Wittenberg, and D. Chen, 2017: ENSO in the CMIP5 simulations: Life cycles, diversity, and responses to climate change. J. Climate, 30, 775-801, https://doi.org/ 10.1175/JCLI-D-15-0901.1.
Chen, D., and Coauthors, 2015: Strong influence of westerly wind bursts on El Niño diversity. Nat. Geosci., 8, 339-345, https:// doi.org/10.1038/ngeo2399.

Choi, J., S.-I. An, and S.-W. Yeh, 2011: Decadal amplitude modulation of two types of ENSO and its relationship with the mean state. Climate Dyn., 38, 2631-2644, https://doi.org/ 10.1007/s00382-011-1186-y.

Chung, P.-H., and T. Li, 2013: Interdecadal relationship between the mean state and El Niño types. J. Climate, 26, 361-379, https://doi.org/10.1175/JCLI-D-12-00106.1.

Coats, S., and K. B. Karnauskas, 2017: Are simulated and observed twentieth century tropical Pacific sea surface temperature trends significant relative to internal variability? Geophys. Res. Lett., 44, 9928-9937, https://doi.org/10.1002/2017GL074622.

Collins, M., and T. C. M. Groups, 2004: El Niño- or La Niña-like climate change? Climate Dyn., 24, 89-104, https://doi.org/ 10.1007/s00382-004-0478-x. , and Coauthors, 2010: The impact of global warming on the tropical Pacific Ocean and El Niño. Nat. Geosci., 3, 391-397, https://doi.org/10.1038/ngeo868.

Collins, W. J., and Coauthors, 2011: Development and evaluation of an Earth-system model-HadGEM2. Geosci. Model Dev., 4, 1051-1075, https://doi.org/10.5194/gmd-4-1051-2011.

Dewitte, B., S.-W. Yeh, B.-K. Moon, C. Cibot, and L. Terray, 2007: Rectification of ENSO variability by interdecadal changes in the equatorial background mean state in a CGCM simulation. J. Climate, 20, 2002-2021, https://doi.org/10.1175/JCLI4110.1.

Di Lorenzo, E., K. M. Cobb, J. C. Furtado, N. Schneider, B. T. Anderson, A. Bracco, M. A. Alexander, and D. J. Vimont, 2010: Central Pacific El Niño and decadal climate change in the North Pacific Ocean. Nat. Geosci., 3, 762-765, https://doi.org/10.1038/ngeo984.

Donner, L. J., and Coauthors, 2011: The dynamical core, physical parameterizations, and basic simulation characteristics of the atmospheric component AM3 of the GFDL global coupled model CM3. J. Climate, 24, 3484-3519, https://doi.org/10.1175/ 2011JCLI3955.1.

Dufresne, J. L., and Coauthors, 2013: Climate change projections using the IPSL-CM5 Earth system model: From CMIP3 to CMIP5. Climate Dyn., 40, 2123-2165, https://doi.org/10.1007/ s00382-012-1636-1.

Dunne, J. P., and Coauthors, 2012: GFDL's ESM2 global coupled climate-carbon earth system models. Part I: Physical formulation and baseline simulation characteristics. J. Climate, 25, 6646-6665, https://doi.org/10.1175/JCLI-D-11-00560.1.

Eyring, V., S. Bony, G. A. Meehl, C. A. Senior, B. Stevens, R. J. Stouffer, and K. E. Taylor, 2016: Overview of the Coupled Model Intercomparison Project Phase 6 (CMIP6) experimental design and organization. Geosci. Model Dev., 9, 19371958, https://doi.org/10.5194/gmd-9-1937-2016.

Fogli, P. G., and Coauthors, 2009: INGV-CMCC carbon (ICC): A carbon cycle earth system model. CMCC Research Paper 61, 31 pp., http://www.cmcc.it/publications-meetings/publications/ research-papers/rp0061-ingv-cmcc-carbon-icc-a-carbon-cycleearth-system-model.

Frauen, C., D. Dommenget, N. Tyrrell, M. Rezny, and S. Wales, 2014: Analysis of the nonlinearity of El Niño-Southern Oscillation teleconnections. J. Climate, 27, 6225-6244, https://doi.org/10.1175/ JCLI-D-13-00757.1.

Freund, M. B., B. J. Henley, D. J. Karoly, H. V. McGregor, N. J. Abram, and D. Dommenget, 2019: Higher frequency of central Pacific El Niño events in recent decades relative to past centuries. Nat. Geosci., 12, 450-455, https://doi.org/10.1038/ s41561-019-0353-3. 
Gent, P. R., and Coauthors, 2011: The Community Climate System Model version 4. J. Climate, 24, 4973-4991, https://doi.org/ 10.1175/2011JCLI4083.1.

Gettelman, A., and Coauthors, 2019: High climate sensitivity in the Community Earth System Model version 2 (CESM2). Geophys. Res. Lett., 46, 8329-8337, https://doi.org/10.1029/ 2019GL083978.

Giorgetta, M. A., and Coauthors, 2013: Climate and carbon cycle changes from 1850 to 2100 in MPI-ESM simulations for the Coupled Model Intercomparison Project phase 5. J. Adv. Model. Earth Syst., 5, 572-597, https://doi.org/ 10.1002/jame.20038.

Graham, F. S., A. T. Wittenberg, J. N. Brown, S. J. Marsland, and N. J. Holbrook, 2017: Understanding the double peaked El Niño in coupled GCMs. Climate Dyn., 48, 2045-2063, https:// doi.org/10.1007/s00382-016-3189-1.

Graham, N. E., 1994: Decadal-scale climate variability in the tropical and north Pacific during the 1970s and 1980s-Observations and model results. Climate Dyn., 10, 135-162, https://doi.org/10.1007/ BF00210626.

Guan, C., and M. J. McPhaden, 2016: Ocean processes affecting the twenty-first-century shift in ENSO SST variability. J. Climate, 29, 6861-6879, https://doi.org/10.1175/JCLI-D-15-0870.1.

Guilyardi, E., 2005: El Niño-mean state-seasonal cycle interactions in a multi-model ensemble. Climate Dyn., 26, 329-348, https://doi.org/10.1007/s00382-005-0084-6.

Ham, Y.-G., and J.-S. Kug, 2011: How well do current climate models simulate two types of El Niño? Climate Dyn., 39, 383398, https://doi.org/10.1007/s00382-011-1157-3.

_ _ - J.-Y. Park, and F.-F. Jin, 2013: Sea surface temperature in the north tropical Atlantic as a trigger for El Niño/Southern Oscillation events. Nat. Geosci., 6, 112-116, https://doi.org/ 10.1038/ngeo1686.

Hare, S. R., and N. J. Mantua, 2000: Empirical evidence for North Pacific regime shifts in 1977 and 1989. Prog. Oceanogr., 47, 103-145, https://doi.org/10.1016/S0079-6611(00)00033-1.

Held, I. M., and B. J. Soden, 2006: Robust responses of the hydrological cycle to global warming. J. Climate, 19, 5686-5699, https://doi.org/10.1175/JCLI3990.1.

Henley, B. J., J. Gergis, D. J. Karoly, S. Power, J. Kennedy, and C. K. Folland, 2015: A tripole index for the interdecadal Pacific oscillation. Climate Dyn., 45, 3077-3090, https://doi.org/10.1007/ s00382-015-2525-1.

— , and Coauthors, 2017: Spatial and temporal agreement in climate model simulations of the interdecadal Pacific oscillation. Environ. Res. Lett., 12, 044011, https://doi.org/10.1088/ 1748-9326/aa5cc8.

Hu, S., and A. V. Fedorov, 2018: Cross-equatorial winds control El Niño diversity and change. Nat. Climate Change, 8, 798-802, https://doi.org/10.1038/s41558-018-0248-0.

Hu, Z.-Z., A. Kumar, H.-L. Ren, H. Wang, M. L'Heureux, and F.-F. Jin, 2013: Weakened interannual variability in the tropical Pacific Ocean since 2000. J. Climate, 26, 2601-2613, https:// doi.org/10.1175/JCLI-D-12-00265.1.

Iizumi, T., J.-J. Luo, A. J. Challinor, G. Sakurai, M. Yokozawa, H. Sakuma, M. E. Brown, and T. Yamagata, 2014: Impacts of El Niño Southern Oscillation on the global yields of major crops. Nat. Commun., 5, 3712, https://doi.org/10.1038/ ncomms 4712 .

Ji, D., and Coauthors, 2014: Description and basic evaluation of Beijing Normal University Earth System Model (BNU-ESM) version 1. Geosci. Model Dev., 7, 2039-2064, https://doi.org/ 10.5194/gmd-7-2039-2014.
Kao, H.-Y., and J.-Y. Yu, 2009: Contrasting eastern-Pacific and central-Pacific types of ENSO. J. Climate, 22, 615-632, https:// doi.org/10.1175/2008JCLI2309.1.

Karnauskas, K. B., R. Seager, A. Kaplan, Y. Kushnir, and M. A. Cane, 2009: Observed strengthening of the zonal sea surface temperature gradient across the equatorial Pacific Ocean. J. Climate, 22, 4316-4321, https://doi.org/10.1175/2009JCLI2936.1.

Kim, S. T., and J.-Y. Yu, 2012: The two types of ENSO in CMIP5 models. Geophys. Res. Lett., 39, L11704, https://doi.org/ 10.1029/2012gl052006.

Knutti, R., D. Masson, and A. Gettelman, 2013: Climate model genealogy: Generation CMIP5 and how we got there. Geophys. Res. Lett., 40, 1194-1199, https://doi.org/10.1002/grl.50256.

Kohyama, T., and D. L. Hartmann, 2017: Nonlinear ENSO Warming Suppression (NEWS). J. Climate, 30, 4227-4251, https://doi.org/10.1175/JCLI-D-16-0541.1.

$\longrightarrow,-\longrightarrow$, and D. S. Battisti, 2017: La Niña-like mean-state response to global warming and potential oceanic roles. J. Climate, 30, 4207-4225, https://doi.org/10.1175/JCLI-D-16-0441.1.

Kosaka, Y., and S.-P. Xie, 2013: Recent global-warming hiatus tied to equatorial Pacific surface cooling. Nature, 501, 403-407, https://doi.org/10.1038/nature12534.

Kug, J.-S., F.-F. Jin, and S.-I. An, 2009: Two types of El Niño events: Cold tongue El Niño and warm pool El Niño. J. Climate, 22, 1499-1515, https://doi.org/10.1175/2008JCLI2624.1.

Larkin, N. K., and D. E. Harrison, 2005: Global seasonal temperature and precipitation anomalies during El Niño autumn and winter. Geophys. Res. Lett., 32, L16705, https://doi.org/10.1029/ 2005GL022860.

Lee, T., and M. J. McPhaden, 2010: Increasing intensity of El Niño in the central-equatorial Pacific. Geophys. Res. Lett., 37, L14603, https://doi.org/10.1029/2010GL044007.

L'Heureux, M. L., D. C. Collins, and Z.-Z. Hu, 2012: Linear trends in sea surface temperature of the tropical Pacific Ocean and implications for the El Niño-Southern Oscillation. Climate Dyn. 40, 1223-1236, https://doi.org/10.1007/s00382-012-1331-2.

Li, G., and S.-P. Xie, 2014: Tropical biases in CMIP5 multimodel ensemble: The excessive equatorial Pacific cold tongue and double ITCZ problems. J. Climate, 27, 1765-1780, https:// doi.org/10.1175/JCLI-D-13-00337.1.

Lian, T., D. Chen, J. Ying, P. Huang, and Y. Tang, 2018: Tropical Pacific trends under global warming: El Niño-like or La Niña-like? Natl. Sci. Rev., 5, 810-812, https://doi.org/10.1093/nsr/nwy134.

Liu, Y., and Coauthors, 2017: Recent enhancement of central Pacific El Niño variability relative to last eight centuries. Nat. Commun., 8, 15386, https://doi.org/10.1038/ncomms15386.

Liu, Z., and E. Lorenzo, 2018: Mechanisms and predictability of pacific decadal variability. Curr. Climate Change Rep., 4, 128144, https://doi.org/10.1007/s40641-018-0090-5.

Lloyd, J., E. Guilyardi, H. Weller, and J. Slingo, 2009: The role of atmosphere feedbacks during ENSO in the CMIP3 models. Atmos. Sci. Lett., 10, 170-176, https://doi.org/10.1002/asl.227.

Long, M. C., K. Lindsay, S. Peacock, J. K. Moore, and S. C. Doney, 2013: Twentieth-century oceanic carbon uptake and storage in CESM1(BGC). J. Climate, 26, 6775-6800, https://doi.org/ 10.1175/JCLI-D-12-00184.1.

Lübbecke, J. F., and M. J. McPhaden, 2014: Assessing the twentyfirst-century shift in ENSO variability in terms of the Bjerknes stability index. J. Climate, 27, 2577-2587, https://doi.org/ 10.1175/JCLI-D-13-00438.1.

Luo, J.-J., W. Sasaki, and Y. Masumoto, 2012: Indian Ocean warming modulates Pacific climate change. Proc. Natl. Acad. Sci. USA, 109, 18 701-18 706, https://doi.org/10.1073/pnas.1210239109. 
Mann, M. E., M. Cane, S. E. Zebiak, and A. Clement, 2005: Volcanic and solar forcing of the tropical Pacific over the past 1000 years. J. Climate, 18, 447-456, https://doi.org/10.1175/ JCLI-3276.1.

Mantua, N. J., S. R. Hare, Y. Zhang, J. M. Wallace, and R. C. Francis, 1997: A Pacific interdecadal climate oscillation with impacts on salmon production. Bull. Amer. Meteor. Soc., 78 , 1069-1079, https://doi.org/10.1175/1520-0477(1997)078<1069: apicow $>2.0 . \mathrm{co} ; 2$.

McPhaden, M. J., T. Lee, and D. McClurg, 2011: El Niño and its relationship to changing background conditions in the tropical Pacific Ocean. Geophys. Res. Lett., 38, L15709, https://oi.org/ 10.1029/2011gl048275.

Meehl, G. A., and Coauthors, 2013: Climate change projections in CESM1(CAM5) compared to CCSM4. J. Climate, 26, 62876308, https://doi.org/10.1175/JCLI-D-12-00572.1.

Meinshausen, M., and Coauthors, 2011: The RCP greenhouse gas concentrations and their extensions from 1765 to 2300. Climatic Change, 109, 213-241, https://doi.org/10.1007/s10584-011-0156-z.

- and Coauthors, 2020: The SSP greenhouse gas concentrations and their extensions to 2500. Geosci. Model Dev., https:// doi.org/10.5194/gmd-2019-222, in press.

Miller, R. L., and Coauthors, 2014: CMIP5 historical simulations (1850-2012) with GISS ModelE2. J. Adv. Model. Earth Syst., 6, 441-478, https://doi.org/10.1002/2013MS000266.

Neelin, J. D., F. F. Jin, and H. H. Syu, 2000: Variations in ENSO phase locking. J. Climate, 13, 2570-2590, https://doi.org/ 10.1175/1520-0442(2000)013<2570:VIEPL>2.0.CO;2.

Newman, M., G. P. Compo, and M. A. Alexander, 2003: ENSOforced variability of the Pacific decadal oscillation. J. Climate, 16, 3853-3857, https://doi.org/10.1175/1520-0442(2003)016<3853 EVOTPD $>2.0 . \mathrm{CO} ; 2$.

- , S.-I. Shin, and M. A. Alexander, 2011: Natural variation in ENSO flavors. Geophys. Res. Lett., 38, L14705, https://doi.org/ 10.1029/2011GL047658.

Power, S., T. Casey, C. Folland, A. Colman, and V. Mehta, 1999: Inter-decadal modulation of the impact of ENSO on Australia. Climate Dyn., 15, 319-324, https://doi.org/10.1007/ s003820050284.

Qiao, F., Z. Song, Y. Bao, Y. Song, Q. Shu, C. Huang, and W. Zhao, 2013: Development and evaluation of an Earth System Model with surface gravity waves. J. Geophys. Res. Oceans, 118, 4514-4524, https://doi.org/10.1002/jgrc.20327.

Rasmusson, E. M., and T. H. Carpenter, 1982: Variation in tropical sea surface temperature and surface wind fields associated with the Southern Oscillation/El Niño. Mon. Wea. Rev., 110, 354-384, https://doi.org/10.1175/1520-0493(1982)110<0354: VITSST $>2.0 . \mathrm{CO} ; 2$

Rayner, N. A., D. E. Parker, and E. B. Horton, 2003: Global analyses of sea surface temperature, sea ice, and night marine air temperature since the late nineteenth century. J. Geophys. Res., 108, 4407, https://doi.org/10.1029/2002JD002670.

Ren, H.-L., and F.-F. Jin, 2011: Niño indices for two types of ENSO. Geophys. Res. Lett., 38, L04704, https://doi.org/ 10.1029/2010GL046031.

Roeckner, E., and Coauthors, 2003: The atmospheric general circulation model ECHAM 5. Part I: Model description. MPI Rep. 349, 140 pp., https://www.mpimet.mpg.de/fileadmin/models/ echam/mpi_report_349.pdf.

Rotstayn, L. D., S. J. Jeffrey, M. A. Collier, S. M. Dravitzki, A. C. Hirst, J. I. Syktus, and K. K. Wong, 2012: Aerosol- and greenhouse gas-induced changes in summer rainfall and circulation in the Australasian region: A study using single- forcing climate simulations. Atmos. Chem. Phys., 12, 63776404, https://doi.org/10.5194/acp-12-6377-2012.

Sakamoto, T. T., and Coauthors, 2012: MIROC4h-A new highresolution atmosphere-ocean coupled general circulation model. J. Meteor. Soc. Japan, 90, 325-359, https://doi.org/ 10.2151/jmsj.2012-301.

Seager, R., M. Cane, N. Henderson, D.-E. Lee, R. Abernathey, and H. Zhang, 2019: Strengthening tropical Pacific zonal sea surface temperature gradient consistent with rising greenhouse gases. Nat. Climate Change, 9, 517-522, https://doi.org/10.1038/ s41558-019-0505-x.

Solomon, A., and M. Newman, 2012: Reconciling disparate twentieth-century Indo-Pacific Ocean temperature trends in the instrumental record. Nat. Climate Change, 2, 691-699, https://doi.org/10.1038/nclimate1591.

Stuecker, M. F., A. Timmermann, F.-F. Jin, S. McGregor, and H.-L. Ren, 2013: A combination mode of the annual cycle and the El Niño/Southern Oscillation. Nat. Geosci., 6, 540-544, https://doi.org/10.1038/ngeo1826.

Sullivan, A., J.-J. Luo, A. C. Hirst, D. Bi, W. Cai, and J. He, 2016: Robust contribution of decadal anomalies to the frequency of central-Pacific El Niño. Sci. Rep., 6, 38540, https://doi.org/10.1038/srep38540.

Sun, D. Z., and Z. Y. Liu, 1996: Dynamic ocean-atmosphere coupling: A thermostat for the tropics. Science, 272, 1148-1150, https://doi.org/10.1126/science.272.5265.1148.

Taschetto, A. S., A. S. Gupta, N. C. Jourdain, A. Santoso, C. C. Ummenhofer, and M. H. England, 2014: Cold tongue and warm pool ENSO events in CMIP5: Mean state and future projections. J. Climate, 27, 2861-2885, https://doi.org/10.1175/JCLI-D-13-00437.1.

Tatebe, H., Y. Imada, M. Mori, M. Kimoto, and H. Hasumi, 2013: Control of decadal and bidecadal climate variability in the tropical Pacific by the off-equatorial South Pacific Ocean. J. Climate, 26, 6524-6534, https://doi.org/10.1175/JCLI-D-12-00137.1.

Taylor, K. E., R. J. Stouffer, and G. A. Meehl, 2012: An overview of CMIP5 and the experiment design. Bull. Amer. Meteor. Soc., 93, 485-498, https://doi.org/10.1175/BAMS-D-11-00094.1.

Timmermann, A., and Coauthors, 2018: El Niño-Southern Oscillation complexity. Nature, 559, 535-545, https://doi.org/10.1038/s41586018-0252-6.

Trenberth, K. E., and D. P. Stepaniak, 2001: Indices of El Niño evolution. J. Climate, 14, 1697-1701, https://doi.org/10.1175/ 1520-0442(2001)014<1697:LIOENO > 2.0.CO;2.

Tziperman, E., L. Stone, M. Cane, and H. Jarosh, 1994: El Niño chaos: Overlapping of resonances between the seasonal cycle and the Pacific Ocean-atmosphere oscillator. Science, 264, 7274, https://doi.org/10.1126/science.264.5155.72.

Vecchi, G. A., B. J. Soden, A. T. Wittenberg, I. M. Held, A. Leetmaa, and M. J. Harrison, 2006: Weakening of tropical Pacific atmospheric circulation due to anthropogenic forcing. Nature, 441, 73-76, https://doi.org/10.1038/nature04744.

Voldoire, A., and Coauthors, 2012: The CNRM-CM5.1 global climate model: Description and basic evaluation. Climate Dyn., 40, 2091-2121, https://doi.org/10.1007/s00382-011-1259-y.

Volodin, E. M., N. A. Dianskii, and A. V. Gusev, 2010: Simulating present-day climate with the INMCM4.0 coupled model of the atmospheric and oceanic general circulations. Izv. Atmos. Oceanic Phys., 46, 414-431, https://doi.org/10.1134/S000143381004002X.

Wang, B., X. Luo, Y.-M. Yang, W. Sun, M. A. Cane, W. Cai, S.-W. Yeh, and J. Liu, 2019: Historical change of El Niño properties sheds light on future changes of extreme El Niño. Proc. Natl. Acad. Sci. USA, 116, 22 512-22 517, https://doi.org/10.1073/pnas.1911130116.

Ward, P. J., B. Jongman, M. Kummu, M. D. Dettinger, F. C. Sperna Weiland, and H. C. Winsemius, 2014: Strong influence of El 
Niño Southern Oscillation on flood risk around the world. Proc. Natl. Acad. Sci. USA, 111, 15 659-15 664, https://doi.org/ 10.1073/pnas.1409822111.

Watanabe, M., and Coauthors, 2010: Improved climate simulation by MIROC5: Mean states, variability, and climate sensitivity. J. Climate, 23, 6312-6335, https://doi.org/10.1175/2010JCLI3679.1.

Watanabe, S., and Coauthors, 2011: MIROC-ESM 2010: Model description and basic results of CMIP5-20c3m experiments. Geosci. Model Dev., 4, 845-872, https://doi.org/10.5194/gmd-4-845-2011.

Wengel, C., 2018: Seasonal ENSO phase locking in the Kiel Climate Model: The importance of the equatorial cold sea surface temperature bias. Climate Dyn., 50, 901-919, https:// doi.org/10.1007/s00382-017-3648-3.

Wittenberg, A. T., 2009: Are historical records sufficient to constrain ENSO simulations? Geophys. Res. Lett., 36, L12702, https://doi.org/10.1029/2009GL038710.

_ _ A. Rosati, N.-C. Lau, and J. J. Ploshay, 2006: GFDL's CM2 global coupled climate models. Part III: Tropical Pacific climate and ENSO. J. Climate, 19, 698-722, https://doi.org/10.1175/JCLI3631.1.

Wu, T., and Coauthors, 2008: The Beijing Climate Center atmospheric general circulation model: Description and its performance for the present-day climate. Climate Dyn., 34, 123147, https://doi.org/10.1007/s00382-008-0487-2.
Yeh, S.-W., J.-S. Kug, B. Dewitte, M.-H. Kwon, B. P. Kirtman, and F.-F. Jin, 2009: El Niño in a changing climate. Nature, 461, 511-514, https://doi.org/10.1038/nature08316.

_ B. P. Kirtman, J.-S. Kug, W. Park, and M. Latif, 2011: Natural variability of the central Pacific El Niño event on multicentennial timescales. Geophys. Res. Lett., 38, L02704, https:/ doi.org/10.1029/2010g1045886.

_- X. Wang, C. Wang, and B. Dewitte, 2015: On the relationship between the North Pacific climate variability and the central Pacific El Niño. J. Climate, 28, 663-677, https://doi.org/ 10.1175/JCLI-D-14-00137.1.

Yukimoto, S., and Coauthors, 2012: A new global climate model of the Meteorological Research Institute: MRI-CGCM3-model description and basic performance. J. Meteor. Soc. Japan, 90A, 23-64, https://doi.org/10.2151/jmsj.2012-a02.

Zhang, H., A. Clement, and P. Di Nezio, 2014: The South Pacific meridional mode: A mechanism for ENSO-like variability. J. Climate, 27, 769-783, https://doi.org/10.1175/JCLI-D-1300082.1.

Zhao, M., H. H. Hendon, O. Alves, G. Liu, and G. Wang, 2016: Weakened eastern Pacific El Niño predictability in the early twenty-first century. J. Climate, 29, 6805-6822, https://doi.org/ 10.1175/JCLI-D-15-0876.1. 
Copyright of Journal of Climate is the property of American Meteorological Society and its content may not be copied or emailed to multiple sites or posted to a listserv without the copyright holder's express written permission. However, users may print, download, or email articles for individual use. 


\section{University Library}

\section{- M M N E R VA A gateway to Melbourne's research publications}

Minerva Access is the Institutional Repository of The University of Melbourne

Author/s:

Freund, MB;Brown, JR;Henley, BJ;Karoly, DJ;Brown, JN

Title:

Warming Patterns Affect El Nino Diversity in CMIP5 and CMIP6 Models

Date:

2020-10-01

Citation:

Freund, M. B., Brown, J. R., Henley, B. J., Karoly, D. J. \& Brown, J. N. (2020). Warming Patterns Affect El Nino Diversity in CMIP5 and CMIP6 Models. Journal of Climate, 33 (19), pp.8237-8260. https://doi.org/10.1175/JCLI-D-19-0890.1.

Persistent Link:

http://hdl.handle.net/11343/274697 